\title{
Improvements in Digestion Protocols for Trace Element and Isotope Determinations in Stream and Lake Sediment Reference Materials (JSd-1, JSd-2, JSd-3, JLk-1 and LKSD-1)
}

\author{
Sidonie Révillon ${ }^{1,2, *}$ and Danièle Hureau-Mazaudier ${ }^{1}$ \\ ${ }^{1}$ Université de Brest, CNRS, UMR 6538 Domaines Océaniques, Institut Universitaire Européen de la Mer, Place \\ Copernic, 29280 Plouzané, France \\ 2 IFREMER, Département Géosciences Marine, BP 70, 29280 Plouzané, France \\ *: Corresponding author : S. Révillon, Tel: +33 (2)29 0085 41, Fax: +33(2)98 8845 70, email address : \\ srevillo@ifremer.fr
}

\begin{abstract}
:
Total dissolution is a critical step in geochemical analysis. Despite the number of published protocols, this issue still draws attention for sediment samples, which are particularly difficult to dissolve due to the common occurrence and high abundance of refractory phases such as zircon. We present tests of different chemical digestion procedures carried out on reference materials (RM) of stream (JSd-1, JSd-2 and JSd-3) and lake (JLk-1 and LKSD-1) sediments from the Geological Survey of Japan (GSJ) and the Canadian Certified Reference Material Programme (CCRPM). We demonstrate that the fusion technique is not appropriate for our studies as not all elements of interest were recovered and blank levels were too high to permit further $\mathrm{Sr}$ and $\mathrm{Pb}$ isotopic composition measurements. Similarly, conventional $\mathrm{HF}+\mathrm{HNO}_{3}$ dissolution methods were not efficient enough for detrital samples. Our preferred method involved using high pressure Teflon ${ }^{\circledR}$ vessel bombs in association with $\mathrm{HClO}_{4}$. This protocol ensured a complete dissolution of the powder, as well as a complete recovery of trace elements. Moreover, blank levels were sufficiently low that $\mathrm{Sr}$ or $\mathrm{Pb}$ isotope compositions could be measured from the same mother solution. We also tested the homogeneity of RM powders by performing tests on various amount of powder.
\end{abstract}

\begin{abstract}
Résumé:
La dissolution totale d'un échantillon est une phase critique pour toute analyse géochimique. Malgré le nombre de protocoles publiés, la mise en solution d'échantillons de sédiments reste problématique en raison de la présence de phases réfractaires comme les zircons. Nous présentons des tests de différentes procédures chimiques réalisés sur des Matériaux de Référence (RM) de sédiments de ruisseau (JSd-1, JSd-2 et JSd-3) et de lac (JLk-1 et LKSD-1) du Service Geologique de Japon (GSJ) et de Canadian Certified Reference Material Programme (CCRPM). Nous montrons que la technique de fusion utilisée n'est pas appropriée à nos études car tous les éléments d'intérêt ne sont pas récupérés quantitativement et le niveau des blancs est trop élevé pour permettre l'analyse des compositions isotopiques de $\mathrm{Sr}$ et de $\mathrm{Pb}$ à partir des mêmes solutions. De même, les techniques de mise en solution conventionnelles par attaque acide $\mathrm{HF}+\mathrm{HNO}_{3}$ sur plaque chauffante ne sont pas suffisamment efficaces pour une mise en solution complète de sédiments détritiques. Notre méthode préférée implique l'utilisation de bombes en téflon et de $\mathrm{HClO}_{4}$. Ce protocole permet la mise en solution totale des échantillons et la récupération de tous les éléments trace intéressants. De plus, les blancs de chimie sont suffisamment bas pour que les compositions isotopiques, e.g., $\mathrm{Sr}, \mathrm{Pb}$ puissent être mesurées à partir du même aliquot. Par ailleurs, nous avons aussi testé l'homogénéité des RM utilisés en appliquant notre protocole d'attaque sur des quantités de poudre variables.
\end{abstract}

Keywords: RM • HR-ICP-MS • acid digestion • fusion • sediment

Mots-clé: matériel de référence $\bullet H R-I C P-M S \bullet$ dissolution acide • fusion • sédiments 
Révillon and Hureau, revised version

$19 / 10 / 2009$

Sample digestion is a critical stage in the process of chemical analysis of geological material.

Especially since developments of modern multi-element measurement instrumentation, such as ICP-MS, HR-ICP-MS or MC-ICP-MS, which allow fast and highly precise solution analysis but require purest solution for the analytes. Despite the multitude of digestion techniques, complete dissolution of some sample types is still problematic. This is particularly true for sediment samples, which are especially difficult to dissolve due to the occurrence of refractory minerals such as zircons. Numerous studies have been published in the past, presenting various methods including conventional $\mathrm{HF}+\mathrm{HNO}_{3}$ acid dissolution procedures, $\mathrm{HF}+\mathrm{HNO}_{3}+\mathrm{HClO}_{4}$ procedures, with or without the use of high pressure digestion vessels or fusion techniques (Toutain and Meyer 1989,Townsend, et al. 1998, Toutain and Meyer 1989, Makishima and Nakamura 1997, Taicheng, et al. 2002, Liang, et al. 2000, Yamamoto, et al. 2005, Yokoyama, et al. 1999, Dulski 2001, Yu, et al. 2001, Münker 1998, Weis, et al. 2006, Pretorius, et al. 2006). However, few studies were specifically dedicated to sediment RM and there is a need for an efficient and reliable method for detrital sediment dissolution.

Sediment geochemistry is an increasingly attracting domain for the scientific community and numerous marine and continental paleo-environmental and paleo-climatic researches now involve geochemical studies. A usually limiting factor to the use of geochemical data, such as trace element analyses or radiogenic isotope compositions, in sediment provenance or climatic cycle's studies is the number of samples involved. Depending on the sediment accumulation rates, high-resolution investigations of environmental or climatic changes at various time scales require analysing hundreds of samples. Moreover, numerous proxies, used in those investigations, such as stable isotopes or biostratigraphy data, are usually analysed at a cm-scale. In order to consistently compare the various sets of data, it is therefore necessary to achieve similar resolution. In addition, complexity of such natural systems implies multi- 
Révillon and Hureau, revised version $19 / 10 / 2009$

proxy approaches that involve the use of numerous geochemical tracers (e.g. trace elements, Sr, $\mathrm{Nd}, \mathrm{Pb}, \mathrm{Hf}$ isotope compositions).

Hence, it is critical to improve chemical procedures so that large numbers of sedimentary samples can be analysed. Rather than focussing on diminishing the time of sample dissolution, we chose in this study to improve the efficiency of the dissolution procedure together with diminishing as much as possible the blank level so that all trace elements and isotope compositions (including $\mathrm{Pb}$ ) could be analysed from the same mother solution. Several methods were fully tested and we propose a complete protocol for the dissolution of detrital sediment samples.

\section{Analytical methodology}

We have performed tests on various sediment Reference Materials (RM): 3 stream sediments from the Geological Survey of Japan (GSJ, JSd-1, JSd-2, and JSd-3); two lake sediments from the GSJ and the Canadian Certified Reference Material Programme (CCRMP, Jlk-1 and LKSD-1) as well as on a well-characterized granite RM (GS-N from the Centre de Recherches Pétrographiques et Géochimiques, CRPG) and a dolerite (CRPG, WS-E).

\section{Reagents}

Water was deionizied and purified on a millipore water system (mixed-bed resin and filters by Milli-Q®). Hydrochloric (Merck PA) and nitric acid (Merck PA) were distilled on a Quartex ${ }^{\circledR}$ apparatus. Hydrofluoridric (Merck Suprapur ${ }^{\circledR}$ ) acid was distilled on a Teflon ${ }^{\circledR}$ Picrotrace ${ }^{\circledR}$ apparatus. Perchloric (Merck Suprapur ${ }^{\circledR}$ ) acid was subboiled using a two-bottle Teflon ${ }^{\circledR}$ apparatus (Analab, Cleanacid ${ }^{\circledR}$ ). All reagents were diluted following the various procedures with Milli-Q ${ }^{\circledR}$ water. 
Révillon and Hureau, revised version

$19 / 10 / 2009$

\section{Digestion techniques}

Five distinct digestion methods were tested in order to determine the most efficient procedure for sedimentary material digestion. The first one is a fusion method and the four others are conventional acid digestion procedures.

\section{Alkaline fusion}

We tested the alkaline fusion technique developed by Taicheng, et al. (2002) for soils and sediment samples and further tested by Bayon, et al. (In press). It involves alkaline fusion with $\mathrm{NaOH}-\mathrm{Na}_{2} \mathrm{O}_{2}$ as the flux followed by pre-concentration of trace element using $\mathrm{Fe}(\mathrm{OH})_{3}-$ $\mathrm{Ti}(\mathrm{OH})_{4}$ prior to ICP-MS analyses. About $100 \mathrm{mg}$ of sediment RM were weighted and placed in the crucible with $1.2 \mathrm{~g} \mathrm{Na}_{2} \mathrm{O}_{2}$ (pro analysis, Fluka) and $0.6 \mathrm{~g} \mathrm{NaOH}$ (pellets, Riedel-deHaën) and fused in a furnace at $650^{\circ} \mathrm{C}$ for 15 minutes. After cooling, the melt is dissolved and iron hydroxides are precipitated by adding $10 \mathrm{ml}$ of ultra-pure water.

\section{Acid digestion procedures}

$100 \mathrm{mg}$ of powdered sample were carefully weighted in $30 \mathrm{ml}$ Savillex ${ }^{\circledR}$ PFA Teflon ${ }^{\circledR}$ beaker (Method A) or 30 ml PTFE Teflon ${ }^{\circledR}$ vessels designed for our high pressure digestion apparatus (Methods B through D).

\section{Method A:}

This first protocol is a classical acid $\mathrm{HF}-\mathrm{HNO}_{3}$ dissolution method. $3 \mathrm{ml}$ of $\mathrm{HF}\left(24 \mathrm{~mol} \mathrm{l}^{-1}\right)$ and $1 \mathrm{ml}$ of $\mathrm{HNO}_{3}\left(14 \mathrm{~mol} \mathrm{l}^{-1}\right)$ were slowly added to the weighted sample to avoid drastic reaction. The Savillex ${ }^{\circledR}$ beakers were tightly closed and agitated for $20 \mathrm{mn}$ in an ultrasonic bath. Beakers were placed on a hot plate at $130^{\circ} \mathrm{C}$ for $48 \mathrm{~h}$. Solutions were dried at $80^{\circ} \mathrm{C}$ for about $12 \mathrm{~h}$ to ensure complete evaporation of HF. The temperature of the hot plate was then 
Révillon and Hureau, revised version

$19 / 10 / 2009$

increased to $120^{\circ} \mathrm{C}$ until complete dryness. The dried residue was dissolved in $1 \mathrm{ml} \mathrm{HCl}$ (6 mol l${ }^{-1}$ ), heated for about $12 \mathrm{~h}$ on a hot plate at $120^{\circ} \mathrm{C}$ and dried again at $120^{\circ} \mathrm{C}$. The dried residue was then dissolved in a mother solution of $\left.40 \mathrm{ml} \mathrm{HCl} \mathrm{(3} \mathrm{mol} \mathrm{l}{ }^{-1}\right)$ (Figure 1).

\section{Method B:}

In method $\mathrm{B}, 3 \mathrm{ml} \mathrm{HF}\left(24 \mathrm{~mol} \mathrm{l}^{-1}\right)$ and $1 \mathrm{ml} \mathrm{HNO}_{3}\left(14 \mathrm{~mol} \mathrm{l}^{-1}\right)$ were carefully added to the weighted sample in PTFE Teflon ${ }^{\circledR}$ vessels and agitated for $20 \mathrm{mn}$ in an ultrasonic bath. Teflon ${ }^{\circledR}$ lids were adjusted on the vessels and transferred into stainless steel high-pressure digestion apparatus. We placed them in an oven to cook at $160^{\circ} \mathrm{C}$ for 7 days. Solutions were then transferred into $30 \mathrm{ml}$ concave bottom Savillex® PFA beakers and, as in Method A, a two-step evaporation procedure was adopted $\left(80^{\circ} \mathrm{C}\right.$ for $12 \mathrm{~h}$ and $120^{\circ} \mathrm{C}$ until complete dryness). The dried residue was dissolved in $\mathrm{HCl}\left(6 \mathrm{~mol} \mathrm{l}^{-1}\right)$, heated and dried before making the mother solution in $40 \mathrm{ml} \mathrm{HCl}\left(3 \mathrm{~mol} \mathrm{l}^{-1}\right)$ (Figure 1).

Method C and $\mathbf{D}$ are identical except for the amount of $\mathrm{HClO}_{4}$ added to the weighted sample. In both methods, $5 \mathrm{ml}$ of $\mathrm{HF}\left(24 \mathrm{~mol} \mathrm{l}^{-1}\right)$ and $1 \mathrm{ml}$ of $\mathrm{HNO}_{3}\left(14 \mathrm{~mol} \mathrm{l}^{-1}\right)$ were added to the sample and $0.2 \mathrm{ml}$ and $1 \mathrm{ml}$ of $\mathrm{HClO}_{4}$ were added in method $\mathrm{C}$ and $\mathrm{D}$, respectively, in PTFE Teflon ${ }^{\circledR}$ vessels. Closed vessels were agitated for $20 \mathrm{mn}$ in an ultrasonic bath, placed in stainless steel high-pressure apparatus and oven-cooked for 7 days at $160^{\circ} \mathrm{C}$. Solutions were then transferred into $30 \mathrm{ml}$ concave bottom Savillex ${ }^{\circledR}$ PFA beakers, dried at $80^{\circ} \mathrm{C}$ for about $12 \mathrm{~h}$ and $120^{\circ} \mathrm{C}$ for about $4 \mathrm{~h}$. Savillex ${ }^{\circledR}$ PFA beakers were then tightly closed and heated in an Analab Evapoclean ${ }^{\circledR}$ apparatus at $160^{\circ} \mathrm{C}$ for about $12 \mathrm{~h}$. Solutions were then dried at $160^{\circ} \mathrm{C}$ for about $12 \mathrm{~h}$ and $180^{\circ} \mathrm{C}$ until complete dryness in an Analab Evapoclean ${ }^{\circledR}$ apparatus. The dried residue was dissolved in $\mathrm{HCl}\left(6 \mathrm{~mol} \mathrm{l}^{-1}\right)$, heated and dried before the mother solution was made in $40 \mathrm{ml} \mathrm{HCl}\left(3 \mathrm{~mol} \mathrm{l}^{-1}\right)$ (Figure 1). 
Révillon and Hureau, revised version

$19 / 10 / 2009$

\section{Trace element analysis}

Measurements were performed on an Element 2 HR-ICP-MS equipped with an ASX 100 auto-sampler at the Institut Universitaire Européen de la Mer (IUEM, Brest, France) using a Tm addition spike technique (Barrat, et al. 1996). The mother solutions in $\mathrm{HCl} 3 \mathrm{~mol} \mathrm{l}^{-1}$ are made up at least $48 \mathrm{~h}$ prior to analysis so that the solutions are properly homogeneous and stable. The day before analysis, $0.95 \mathrm{ml}$ of the mother solution $\left(\mathrm{HCl}, 3 \mathrm{~mol} \mathrm{l}^{-1}\right)$ was carefully weighted; $0.07 \mathrm{ml}$ of Tm spike was added in Savillex ${ }^{\circledR}$ beakers and dried down on a hot plate. Dried residues were dissolved in $0.1 \mathrm{ml}$ concentrated nitric acid and diluted with $14 \mathrm{ml}$ Milli$\mathrm{Q}^{\circledR}$ water just before analysis on the ICP-MS. International rock standard solutions of BHVO-2 or B-EN were used as reference solutions and run after every batch of three samples for the correction of instrumental drift. The measurement settings and calculations using Tm addition follow those of Barrat, et al. 1996) and are further described in Bayon et al (In press).

\section{Results and discussion}

All concentration results are given in Table 1. Mean Values (MV) are reported with the number (n) of solutions made as duplicates. Precision are reported as RSD \%. To test the accuracy of our different procedures, we compared our data with compilations of published reference values. For each RM, published values (n, number of published values used) are averaged and the RSD \% is reported. Differences between our results and averaged published values are also reported as $\Delta(\%)$. We also report averages (in ppb) of total procedural blanks (alkaline fusion and Method D) in Table 1. Our results are also illustrated together with 
Révillon and Hureau, revised version

19/10/2009

published values as spidergrams normalised to UCC (Upper Continental Crust, Taylor and McLennan 1995) (Figures 1-4).

\section{Fusion procedure:}

The main advantage of fusion techniques is to ensure rapid and complete digestion of all rockforming minerals, including highly resistant minerals. The main limitation of this method is, however, potential contamination problems related to the use of impure reagents and metal crucible and incomplete recovery of all elements of interest. As reported in Table 1, blank levels are very high for some elements like $\mathrm{Ba}, \mathrm{Sr}, \mathrm{Pb}$, metals and to a lesser extent $\mathrm{Nb}, \mathrm{Zr}$, and La. Such elevated values rule out any further measurement of $\mathrm{Sr}$ and $\mathrm{Pb}$ isotope compositions but also do not allow the use of these elements for geochemical interpretations. However, we did not used selected very high purity fluxes and it is likely that lower blanks values could be obtained by utilizing higher grade reagent (S. Gallet, pers. com.). It is also clear that the preconcentration procedure do not allow a complete recovery of all elements. In particular, most of $\mathrm{U}, \mathrm{Nb}, \mathrm{Pb}, \mathrm{Cu}$ and $\mathrm{Zn}$ are missing and $\mathrm{V}, \mathrm{Cr}$ and $\mathrm{Ga}$ are not recovered (Figure 1, JSd-1 and Jlk-1). On the other hand, REE, Th, Hf or Y, are fully recovered and blank values are low. This technique can therefore be easily used in the case of geochemical studies focused on these specific elements or dedicated to $\mathrm{Nd}$ and $\mathrm{Hf}$ only isotope compositions analyses.

Despite the rapidity of the technique and its efficiency for some elements (mainly the REE), we decided not to carry on using this procedure because of two main limitations: (1) blank levels and (2) the lack of recovery for some element of interest in our sediment geochemistry studies.

\section{Methods A through C:}


Révillon and Hureau, revised version

$19 / 10 / 2009$

We performed these three methods in order to test whether a total dissolution could be achieved with a conventional $\mathrm{HF}+\mathrm{HNO}_{3}$ digestion procedure (Method $\mathrm{A}$ ), a high pressure digestion apparatus would increase the efficiency of an $\mathrm{HF}+\mathrm{HNO}_{3}$ procedure (Method B) and the minimum amount of $\mathrm{HClO}_{4}$ needed to ensure a complete dissolution in high pressure digestion vessels (Method C).

The most significant difference between results of method A and the others is that $\mathrm{Zr}$ and $\mathrm{Hf}$ are not recovered. This clearly indicate that the Method A is unable to dissolve highly refractory minerals and most likely zircons as previously shown for granite RM (Yu, et al. 2001). It is particularly seen in RM JSd-1 in which respectively $~ 21 \%$ and $\sim 28 \%$ of $\mathrm{Zr}$ and Hf are recovered (Table 1). For RM JSd-2 and JSd-3, 75\% Zr, 72\% Hf and 65\% Zr and Hf are recovered respectively.

Results obtained with Method B are even worse compared with Method A. Many elements, including the REE are lost during the digestion procedure (Figure 2) and none of the RM gave satisfactory results. We do not expect any problems related to storage duration of the diluted solutions as they were systematically prepared immediately prior to measurements. An explanation to this feature may be that insoluble phases precipitate at high temperature when $\mathrm{HF}$ and $\mathrm{HNO}_{3}$ only are used or that $1 \mathrm{ml}$ of $\mathrm{HCl}$ is insufficient to remove all the fluorides. Such an effect has already been noticed for mafic silicate rocks in which many trace element including the REE precipitate as insoluble fluorides (Yokoyama, et al. 1999). We can also note that the amount of insoluble phase precipitating is probably highly variable as reflected by the relatively high RSD \% values calculated for Method B analyses (Table 1). Another likely possibility is that $3 \mathrm{ml}$ of $\mathrm{HF}$ was not sufficient to dissolve all the silicates resulting in a partial dissolution of the silicate phases. During the course of this set of experiments, we noticed a relationship between the amounts of sample dissolved (varying between 100 and 
Révillon and Hureau, revised version

$19 / 10 / 2009$

$110 \mathrm{mg}$ ) and the low quality of the results. Whenever the sample weight was slightly higher, the quality of the recovery was worse. We concluded that increasing the volume of HF would probably improve the procedure and $5 \mathrm{ml}$ of $\mathrm{HF}$ was used for methods $\mathrm{C}$ and $\mathrm{D}$.

Method C gave satisfactory results for reference material JSd-1, JSd-2 and JSd-3 compared to published values (Table 1, Figure 2). However, we noted that $\mathrm{Zr}$ and Hf results with this method were still slightly lower than the published values and concluded that zircon may have not been completely dissolved (Table 1). In contrast, reference material Jlk-1 gave mitigated results. It is clear from Figure 2 that Jlk-1 was only partially dissolved with method C or that an insoluble phase formed during the dissolution process leading to a partial recovery of the sample in the solution.

\section{Method D:}

For each analysed RM, method D gave the most accurate results compared to the published values. Numerous duplicate solutions were made for each RM (between 6 and 16, Table 1) in order to check the reliability and the reproducibility of the method. We also tested this protocol on well-measured international standards such as dolerite WS-E and granite GS-N (Table 1, Figure 2). Results for WS-E and GS-N are in very good agreement with certified values and RSD \% for our measurements are less than $10 \%$ for most elements. Exceptions to this are mainly Cs, $\mathrm{Nb}$ and to a lesser extend $\mathrm{Pb}$ for GS-N and Nb for WS-E (Table 1). Results for JSd-1 are in fairly good agreement with published values and RSD \% are below 15\% except for Rb and Nb (Table 1). Results for JSd-2 are in good agreement with published values and RSD \% for all elements are below 10\% with the exception of $\mathrm{Nb}$ and $\mathrm{Ta}$, which are however, still below 15\%. Similarly, to JSd-2, results for JSd-3 are in good agreement with published values and have RSD values below 10\% for most elements. Exceptions to this are Cs and $\mathrm{Nb}$, which are about $15 \%$. For an unknown reason, one solution for JSd-2 and one 
Révillon and Hureau, revised version

19/10/2009

for JSd-3 gave very high $\mathrm{Pb}$ contents compared to the others, which drastically increased the calculated RSD to 33\% and 31\% respectively. As these two solutions were run on the same day, one can suspect a contamination problem or a memory effect in the machine at this precise time. Results for Jlk-1 are overall less satisfactory than measurements on stream sediment samples. Calculated RSD are slightly higher around 10 to 15\%. An explanation to these results might reside in the fact that this lake sediment sample contains a consequent amount of organic material ( 15 000 ppm, Imai, et al. 1996) and may therefore decrease the stability of the solution.

As already noticed by Yamamoto et al. (2005), compiled published values for JSd-1 and JSd2 show clear derivations from smooth REE patterns, particularly within the HREE. We compared our results with those of Yamamoto et al. (2005) who performed a two-steps procedure using first an acid dissolution method followed by an alkali fusion method and a cation exchange column for REE separation. Our results are in very good agreement with their results and confirm the fact that compiled published values for HREE may not be the most reliable. This also demonstrates that our method is efficient to recover REE in sedimentary rocks without the use of an alkali fusion step and without separating REE from the matrix (Figure 3).

Results of trace metals analyses (mainly V, Co, Cu, and Ga, Table 1) are overall in good agreement with the published values. Calculated RSD are mostly within 10 to $15 \%$ and below 10\% for reference material WS-E (Table 1). Results for Ni (JSd-1) and Zn (JSd-2 and Jlk-1) are less satisfactory and contamination problems cannot be completely ruled out. Measured Cr contents are not only highly variable but also very different from published data. On average, $50 \%$ of $\mathrm{Cr}$ is lost during the dissolution process and this method can therefore not be used for this element.

\section{Are some reference powders heterogeneous?}


Révillon and Hureau, revised version $19 / 10 / 2009$

In order to check the homogeneity of RM powders we performed several sets of analyses with variable amount of sample (Table 1, Figure 4). For reference material JSd-1, JSd-2, JSd-3 and $\mathrm{Jlk}-1$, there is a good agreement between results obtained for $100 \mathrm{mg}, 200 \mathrm{mg}$ and $400 \mathrm{mg}$ of sample. Slight differences observed in the concentrations are mostly within analytical errors and we concluded that powders for these standards were homogeneous (Table 1, Figure 4). In contrast, reference material LKSD-1 gave highly variable concentrations depending on the amount of sample dissolved. Concentrations are clearly higher in experiments carried with $100 \mathrm{mg}$ (4 duplicates, Table 1) than with $200 \mathrm{mg}$ and $400 \mathrm{mg}$ (two duplicates each, Table 1). Careful examination of the spidergrams, reveals that patterns are strictly parallel suggesting a dilution process (Figure 4). We suggest that the powder contain variable amounts of quartz that can dilute trace element content without fractionation of trace element between each other.

\section{Conclusion}

Sample digestion is a critical stage to ensure high quality geochemical analyses of geological material. It is particularly relevant for sediment analyses, as this type of material is naturally highly heterogeneous and highly resistant to acid dissolution. Occurrence of refractory minerals such as zircon makes it difficult to obtain a complete dissolution of the samples. In this study, we compare various methods of sediment dissolution using different acid associations and high pressure-high temperature Teflon ${ }^{\circledR}$ vessels as well as a fusion technique. We show that the fusion procedure is efficient and rapid but does not allow analysing all element of interest. Moreover, blank levels are very high for some elements ruling out any further $\mathrm{Sr}$ or $\mathrm{Pb}$ isotope composition analyses from the solution. We show that 
Révillon and Hureau, revised version

19/10/2009

$\mathrm{HF}+\mathrm{HNO}_{3}$ digestion procedures are not sufficient to ensure a complete dissolution of refractory phases (Method A), even when placed at high temperature and high pressure for a long period (7 days, method B). We achieve a complete dissolution of our Reference Materials (RM) by adding $\mathrm{HClO}_{4}$ and using stainless steel Teflon® vessels. We also demonstrated that a minimum amount of $\mathrm{HClO}_{4}$ is necessary to ensure a full dissolution (Methods C and D). In order to check its reliability and reproducibility, we have tested our preferred method (method D) on five sediment RM powders: stream sediments JSd-1 (16 duplicates), JSd-2 (7 duplicates) and JSd-3 (6 duplicates) and lake sediments Jlk-1 (8 duplicates) and LKSD-1 (4 duplicates). We further confirmed the reproducibility of our method on well characterised international RM for granite (GS-N, from the Centre de Recherches Pétrographiques et Géochimiques, CRPG) and basalt (WSE, CRPG). Our results indicate that our method allow to obtain a complete dissolution of the sample and a complete recovery of the trace element. Our measured blanks are also very low, which permit to undertake chemical separations for further radiogenic isotope analyses ( $\mathrm{Sr}, \mathrm{Nd}, \mathrm{Pb}, \mathrm{Hf}$ ). Although this protocol seems time-consuming, including numerous steps, we strongly suggest its use for sediment geochemistry studies. The main advantage of our method is that once a mother solution is made up, one can undertake any type of analyse including $\mathrm{Sr}, \mathrm{Nd}$ and $\mathrm{Pb}$ isotope work.

During the course of these experiments, we have also tested the homogeneity of RM powders. We noticed that RM LKSD-1 might be heterogeneous, containing variable amount of quartz that entrains a dilution of trace element content.

\section{Acknowledgments:}

This work was supported by IFREMER and the French CNRS through funding of SR.

Authors are grateful to M. Benoit and C. Bassoulet for their assistance in running the ICP-MS 
Révillon and Hureau, revised version

$19 / 10 / 2009$

at the IUEM, Brest, France. The authors greatly acknowledge N. Mattielli and S. Gallet for

their careful and detailed reviews, which significantly improved the quality of the manuscript.

\section{References}

\section{A.T. Townsend, Z. Yu, P. McGoldrick and J.A. Hutton (1998)}

Precise lead isotope ratios in Australian galena samples by high resolution inductively coupled plasma mass spectrometry, Journal of Analytical Atomic Spectrometry, 13: 809-813.

\section{J. Toutain and G. Meyer (1989)}

Iridium-bearing sublimates at the hot-spot volcano (Piton de la Fournaise, Indian Ocean), Geophysical Research Letters, 16: 1391-1394.

\section{A. Makishima and E. Nakamura (1997)}

Suppression of matrix effects in ICP-MS by high power operation of ICP: application to precise determination of $\mathrm{Rb}, \mathrm{Sr}, \mathrm{Y}, \mathrm{Cs}, \mathrm{Ba}, \mathrm{REE}, \mathrm{Pb}$, Th and $\mathrm{U}$ at ng g-1 levels in miligram silicate samples, Geostandards Newsletter, 21: 307-319.

\section{Taicheng, C. Hangting and Z. Xianjin (2002)}

Determination of rare and rare earth elements in soils and sediments by ICP-MS using $\mathrm{Ti}(\mathrm{OH}) 4-\mathrm{Fe}(\mathrm{OH}) 3$ co-precipitation preconcentration, Journal of Analytical Atomic Spectrometry, 17: 410.

\section{Q. Liang, H. Jing and D.C. Gregoire (2000)}

Determination of trace elements in granites by inductively coupled plasma mass spectrometry, Talanta, 51: 507-513.

K. Yamamoto, F. Yamashita and M. Adachi (2005)

Precise determination of REE for sedimentary reference rocks issued by the Geological Survey of Japan Geochem. J., 39: 289-297

\section{T. Yokoyama, A. Makishima and E. Nakamura (1999)}

Evaluation of the coprecipitation of incompatible trace elements with fluoride during silicate rock dissolution by acid digestion, Chemical Geology, 157: 175-187.

\section{P. Dulski (2001)}

Reference Materials for Geochemical Studies:New analytical data by ICP-MS and critical discussion of reference values, Geostandards Newsletter: The Journal of Geostandards and Geoanalysis 25: 87-125

\section{Z. Yu, P. Robinson and P. McGoldrick (2001)}

An evaluation of methods for the chemical decomposition of geological materials for trace element determination using ICP-MS, Geostandards Newsletter, 25: 199-217.

\section{Münker (1998)}

$\mathrm{Nb} / \mathrm{Ta}$ fractionation in a cambrian arc/back arc system, Nez Zealand: soource constraints and application of refined ICPMS techniques, Chemical Geology, 144: 23-45. 
Révillon and Hureau, revised version

$19 / 10 / 2009$

D. Weis, B. Kieffer, C. Maerschalk, J. Barling, J. De Jong, G. Williams, D. Hanano, W. Pretorius, N. Mattieli, J.S. Scoates, A. Goolaerts, R. Friedman and J.B. Mahoney (2006) High-precision isotopic characterization of USGS reference materials by TIMS and MC-ICPMS, Geochemistry, Geophysics, Geosystems (G3). 7.

W. Pretorius, D. Weis, G. Williams, D. Hanano, B. Kieffer and J.S. Scoates (2006) Complete trace element characterization of granitoid (USGS G-2, GSP-2) reference materials by high resolution inductively coupled plasma-mass spectrometry, Geostandards and Geoanalytical Research, 30: 39-54.

G. Bayon, J.A. Barrat, J. Etoubleau, M. Benoit, C. Bollinger and S. Révillon (In press) Determination of rare earth elements, Sc, Y, Zr, Ba, Hf and Th in geological samples by ICPMS after Tm addition and alkaline fusion, Geostandards and Geoanalytical Research.

\section{J.A. Barrat, F. Keller, J. Amossé, R.N. Taylor, R.W. Nesbitt and T. Hirata (1996)}

Determination of rare earth elements in sixteen silicate reference samples by ICP-MS after Tm addition and ion exchange separation, Geostandards Newsletter, 20: 133-139.

\section{S.R. Taylor and S.M. McLennan (1995)}

The geochemical evolution of the continental crust, Rev. Geophys., 33: 241-265.

N. Imai, S. Terashima, S. Itoh and A. Ando (1996)

compilation of analytical data on nine GSJ geochemical reference samples,"Sedimentary rock series", Geostandards Newsletter, 20: 165-216.

\section{C.-D. Garbe-Schönberg (1993)}

Simultaneous determination of thirty-seven trace elements in twenty-eight international rock standards by ICP-MS, Geostandards Newsletter, 17: 81-97

\section{K. Govindaraju (1994)}

1994 compilation of working values and sample description for 383 geostandards, Geostandards Newsletter, 18: 1-158

\section{S.K. Sahoo, H. Yonehara, K. Kurotaki, K. Shiraishi, V. Ramzaev and A. Barkovski (2001) \\ Determination of rare earth elements, thorium and uranium by inductively coupled plasma mass spectrometry and strontium isotopes by thermal ionization mass spectrometry in soil samples of Bryansk region contaminated due to Chernobyl accident Journal of Radioanalytical and Nuclear Chemistry 247: 341-345}

\section{Table and Figure captions}

\section{Table 1:}

Concentrations measured in reference material JSd-1, JSd-2, JSd-3, Jlk-1, LKSD-1, GS-N and WS-E (ppm) together with average blank values (ppb). MV: mean value; n: number of 
Révillon and Hureau, revised version

$19 / 10 / 2009$

duplicate solutions analysed; RSD: relative standard deviation; $\Delta$ (\%): differences expressed as \% between our results and averaged published values.

\section{Figure 1:}

Flow chart illustrating the different digestion procedure tested in this study.

\section{Figure 2:}

Concentrations normalised to UCC (Upper Continental Crust, Taylor and McLennan 1995) for RMs JSd-1, JSd-2, JSd-3, Jlk-1, LKSD-1, GS-N and WS-E in comparison with published values. For RMs JSd-1, JSd-2 and JSd-3, published values are represented as grey shaded area and are from Yamamoto, et al. 2005, Dulski 2001, Imai, et al. 1996, Garbe-Schönberg 1993, Govindaraju 1994, Sahoo, et al. 2001.

\section{Figure 3:}

Chondrite-normalised REE patterns of RMs JSd-1 and JSd-2 compared to published reference values and results obtained by Yamamoto et al., (2005).

\section{Figure 4:}

Concentrations normalised to UCC for reference material JSd-1, JSd-2, JSd-3, Jlk-1 and LKSD-1 using $100 \mathrm{mg}, 200 \mathrm{mg}$ or $400 \mathrm{mg}$ of powder for the dissolution procedure. 


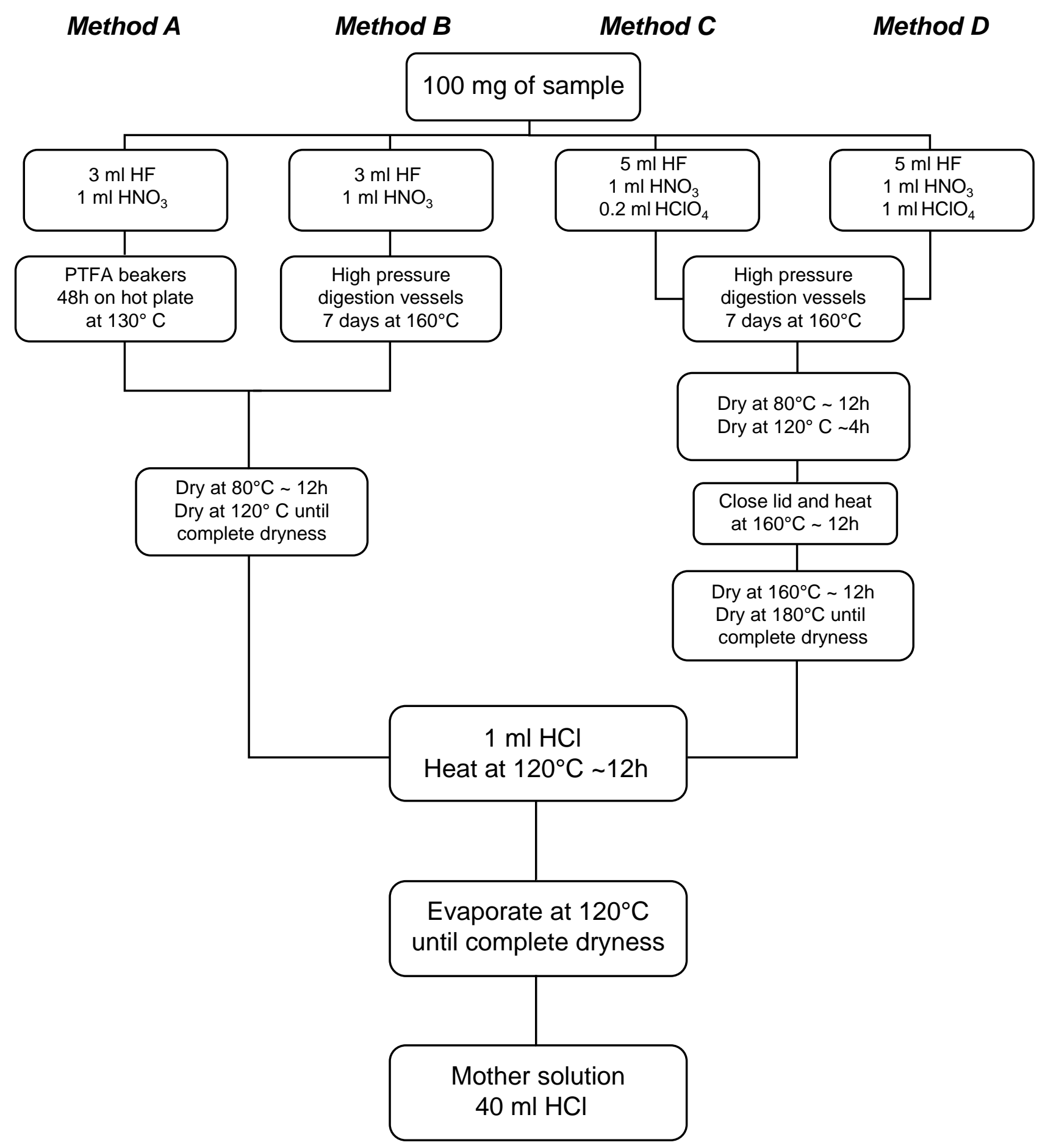

Figure 1 

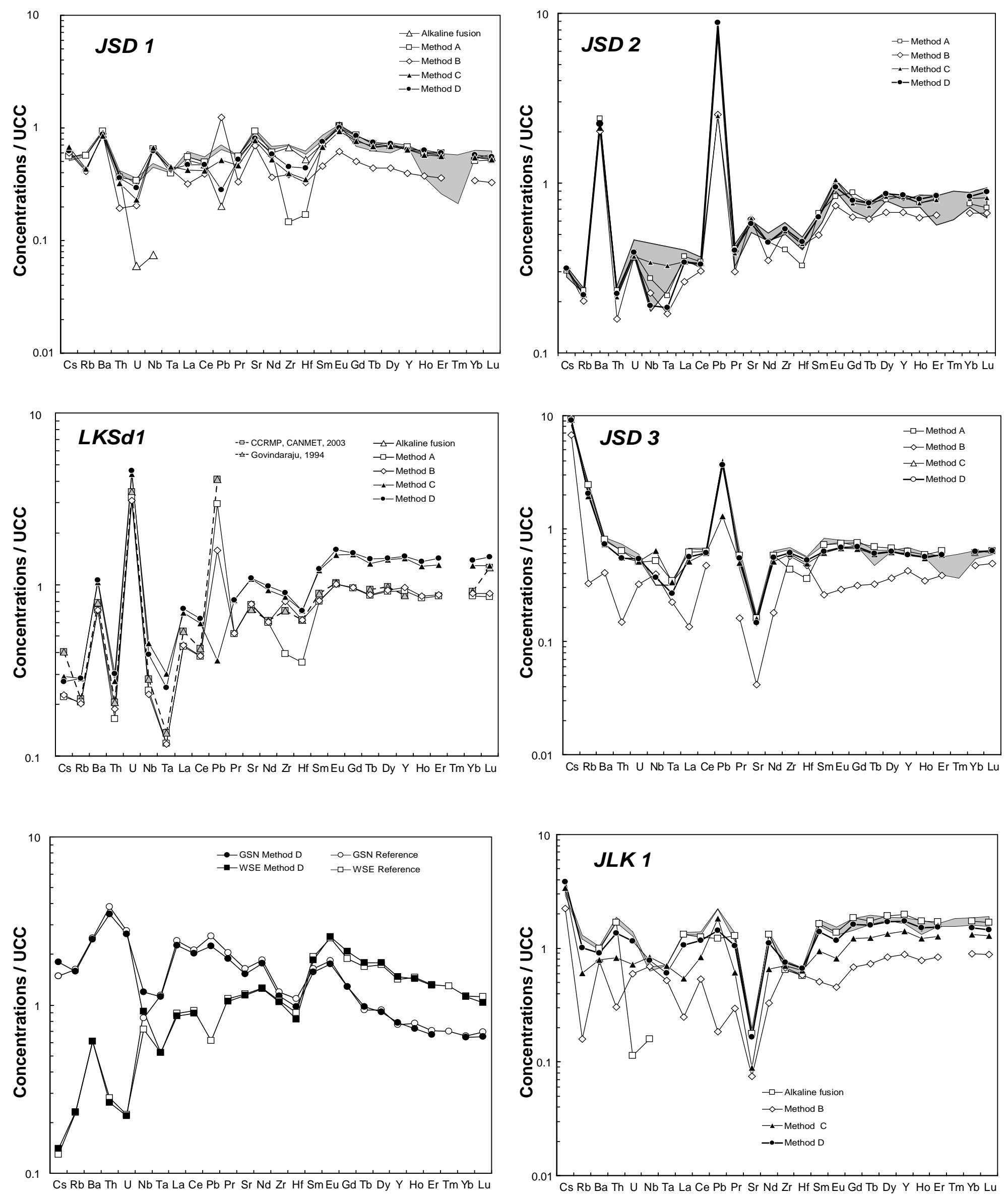

Figure 2 

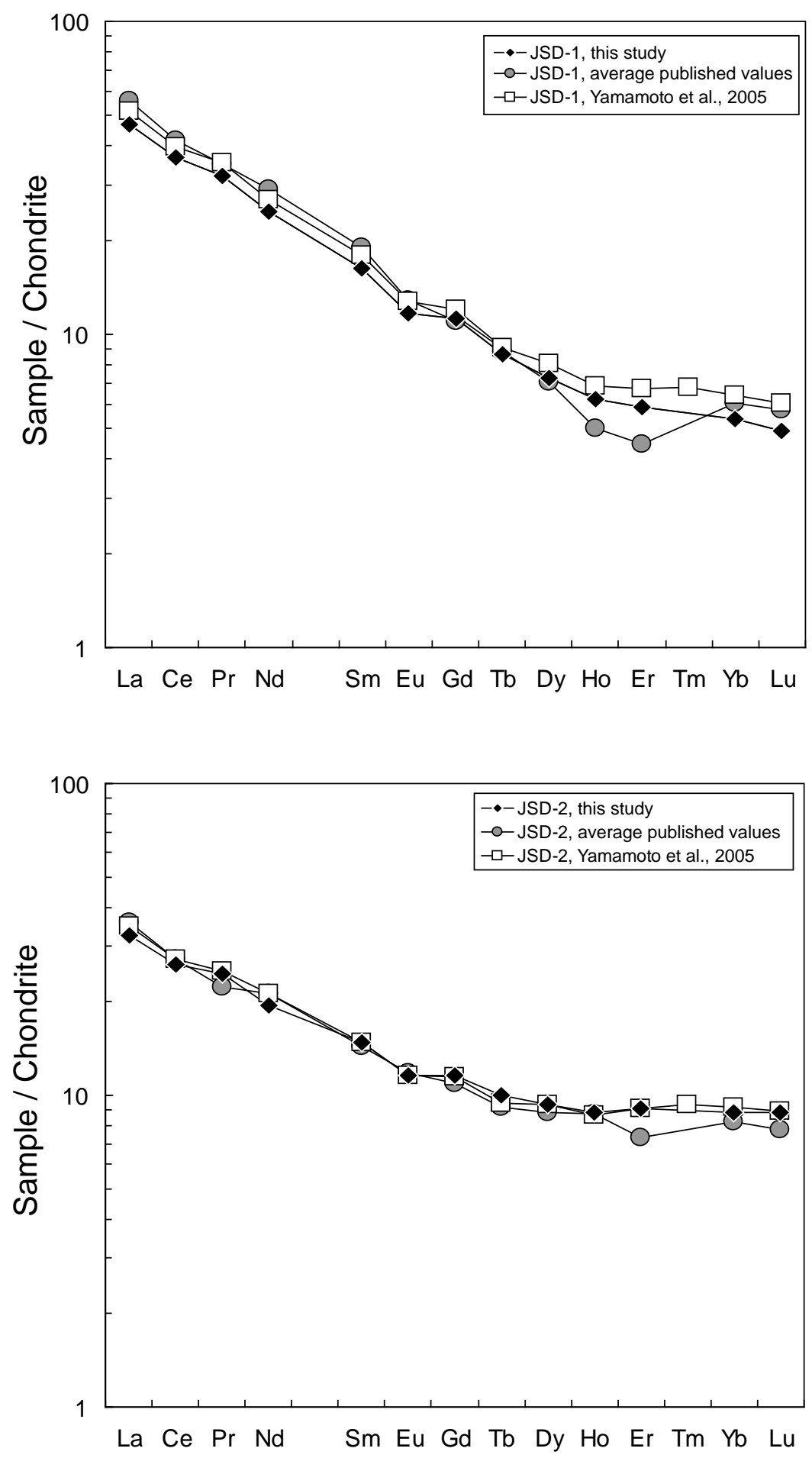

Figure 3 

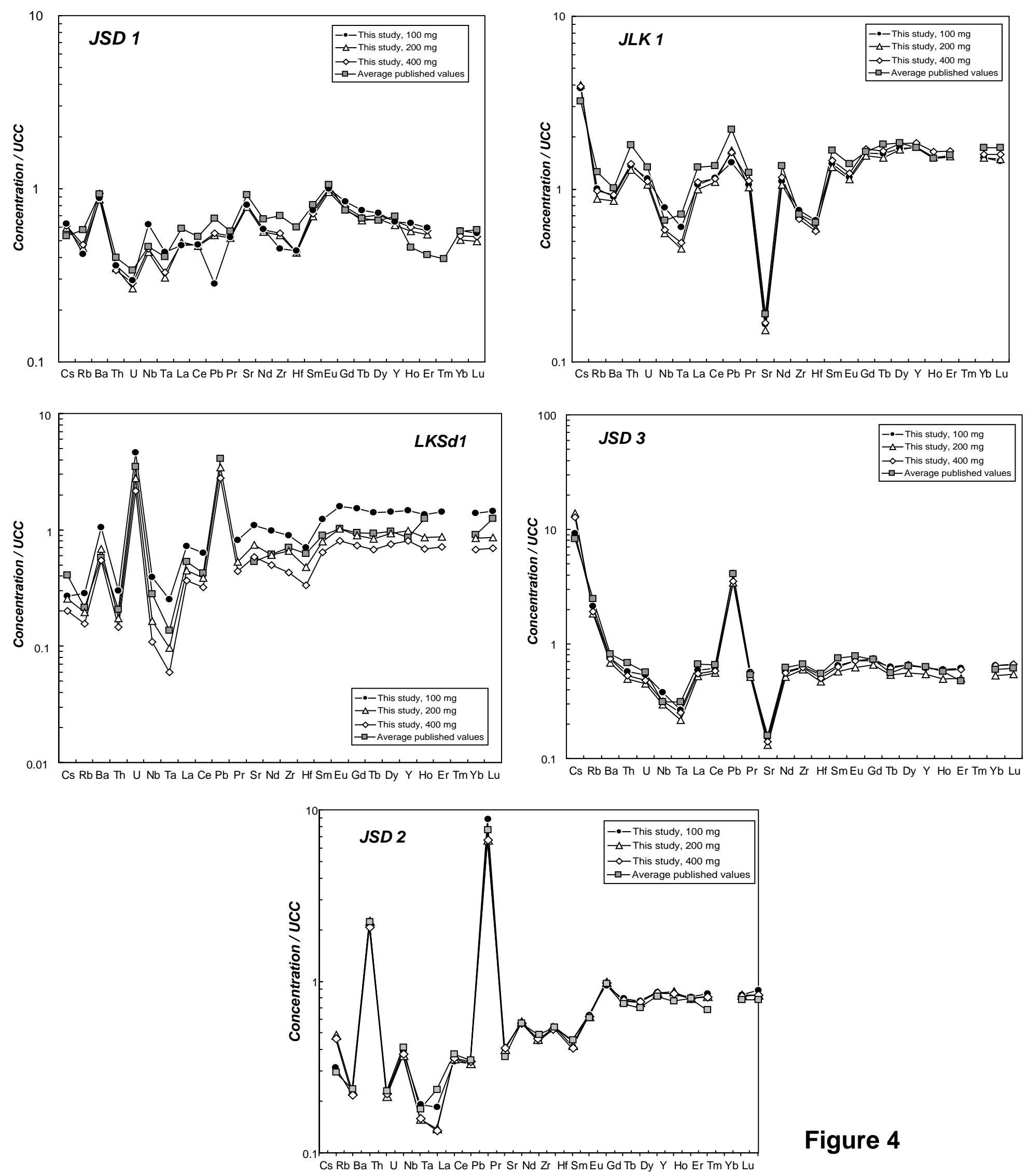

Figure 4 


\begin{tabular}{|c|c|c|c|c|c|c|c|c|c|c|c|c|}
\hline & \multirow{3}{*}{$\begin{array}{c}\text { Blank }(n=14) \\
\text { Method D } \\
\text { ppb }\end{array}$} & \multirow{3}{*}{$\begin{array}{c}\text { Blank }(n=2) \\
\text { Alkaline fusion } \\
\text { ppb }\end{array}$} & \multicolumn{5}{|c|}{ GS-N } & \multicolumn{5}{|c|}{ WS-E } \\
\hline & & & \multicolumn{3}{|c|}{ Method D } & \multicolumn{2}{|c|}{ Published } & \multicolumn{3}{|c|}{ Method D } & \multicolumn{2}{|c|}{ Published } \\
\hline & & & $M V(n=6)$ & $\%$ RDS & $\Delta(\%)$ & $M V(n=4)$ & $\%$ RDS & $M V(n=5)$ & $\%$ RDS & $\Delta(\%)$ & $M V(n=12)$ & $\%$ RDS \\
\hline Cs & 6.08 & 23.14 & 7 & 14.6 & 21.7 & 5.5 & 1.6 & 0.5 & 5.6 & 8.6 & 0.5 & 5.0 \\
\hline $\mathbf{R b}$ & 21.66 & 143.28 & 178 & 15.8 & -3.0 & 183 & 1.2 & 26.0 & 6.7 & 1.5 & 25.6 & 5.4 \\
\hline $\mathbf{B a}$ & 42.57 & 11533.23 & 1354.6 & 4.5 & -1.6 & 1376.3 & 1.3 & 336.0 & 3.4 & 0.5 & 334.3 & 5.1 \\
\hline Th & 0.12 & 5.88 & 37.3 & 5.0 & -9.1 & 41 & 1.7 & 2.8 & 6.4 & -6.1 & 3.0 & 2.8 \\
\hline $\mathbf{U}$ & 0.11 & 1.20 & 7.4 & 8.3 & -3.7 & 7.7 & 2.1 & 0.6 & 3.3 & -1.3 & 0.6 & 3.1 \\
\hline $\mathrm{Nb}$ & 2.35 & 204.53 & 30 & 25.0 & 42.4 & 21 & & 22.9 & 9.7 & 27.0 & 18.0 & 6.1 \\
\hline $\mathrm{Ta}$ & 0.64 & 85.68 & 2 & 19.9 & -1.9 & 2.5 & 5.5 & 1 & 12.6 & 0.4 & 1.1 & 3.0 \\
\hline La & 1.31 & 142.51 & 68.0 & 7.8 & -5.6 & 72 & 3.0 & 25.9 & 2.7 & -3.6 & 26.8 & 2.3 \\
\hline $\mathrm{Ce}$ & 2.58 & 46.44 & 129.4 & 4.4 & -4.7 & 135.9 & 2.3 & 57.1 & 4.6 & -3.2 & 59.0 & 7.8 \\
\hline $\mathrm{Pb}$ & 25.86 & 2141.07 & 44.7 & 7.5 & -13.2 & 51.5 & 4.1 & & & & 12.3 & 9.2 \\
\hline $\mathrm{Pr}$ & 0.31 & 6.09 & 13.4 & 5.5 & -7.2 & 14.5 & 3.1 & 7.4 & 3.8 & -3.6 & 7.7 & 3.0 \\
\hline $\mathrm{Sr}$ & 16.18 & 49095.68 & 533.9 & 6.5 & -7.3 & 576 & 1.5 & 401.0 & 3.2 & -1.5 & 406.9 & 4.2 \\
\hline Nd & 1.21 & 23.21 & 45.9 & 5.9 & -4.5 & 48 & 2.4 & 32.5 & 4.3 & -0.7 & 32.7 & 2.1 \\
\hline $\mathrm{Zr}$ & 4.89 & 687.76 & 214.2 & 5.0 & -5.4 & 226.5 & 8.7 & 198.6 & 6.1 & -1.8 & 202.2 & 5.8 \\
\hline Hf & 1.12 & 4.19 & 5.6 & 4.2 & -10.4 & 6.3 & 4.0 & 4.8 & 9.3 & -8.4 & 5.2 & 4.5 \\
\hline Sm & 0.36 & 5.04 & 7.1 & 4.6 & -3.8 & 7.4 & 2.2 & 8.3 & 5.9 & -4.7 & 8.7 & 3.2 \\
\hline Eu & 0.45 & 7.89 & 1.5 & 4.1 & -4.7 & 1.6 & 4.0 & 2.2 & 6.0 & 1.6 & 2.2 & 3.7 \\
\hline Gd & 1.26 & 6.95 & 5 & 13.8 & -0.3 & 4.9 & 7.3 & 7.9 & 7.6 & 11.2 & 7.1 & 4.0 \\
\hline Tb & 0.09 & 1.37 & 0.6 & 1.3 & 5.0 & 0.6 & 6.7 & 1.1 & 5.8 & 5.4 & 1.1 & 3.5 \\
\hline Dy & 0.21 & 3.70 & 3.2 & 6.1 & -2.5 & 3.3 & 6.6 & 6.3 & 6.7 & 3.6 & 6.1 & 2.9 \\
\hline$Y$ & 1.38 & 26.74 & 17.3 & 4.8 & 2.7 & 16.8 & 7.7 & 32.4 & 5.2 & 3.3 & 31.4 & 6.4 \\
\hline Ho & 0.05 & 0.49 & 0.6 & 7.0 & -7.1 & 0.6 & 9.4 & 1.1 & 1.8 & -1.9 & 1.2 & 4.2 \\
\hline $\mathrm{Er}$ & 0.20 & 1.74 & 1.5 & 3.4 & -5.4 & 1.6 & 9.9 & 3.0 & 4.9 & -0.9 & 3.0 & 3.4 \\
\hline Yb & 0.19 & 1.82 & 1.4 & 9.0 & -1.7 & 1.4 & 2.2 & 2.5 & 5.2 & -0.3 & 2.5 & 2.7 \\
\hline Lu & 0.04 & 0.56 & 0.2 & 6.2 & -6.1 & 0.2 & 3.5 & 0.3 & 6.6 & -7.4 & 0.4 & 4.6 \\
\hline Sc & 1.47 & 12.08 & 7.2 & 6.3 & 1.1 & 7.2 & 3.6 & 30.0 & 7.0 & 8.8 & 27.6 & 3.8 \\
\hline $\mathrm{Ti}$ & 0.11 & 1.13 & 0.7 & 9.3 & & & & 2.4 & 5.7 & & & \\
\hline $\mathbf{V}$ & 12.01 & 188.38 & 60 & 14.8 & -8.2 & 65 & & 340.6 & 3.8 & 3.2 & 330.0 & 4.2 \\
\hline $\mathrm{Cr}$ & 143.53 & 1078.21 & 34 & 59.5 & -38.8 & 55.2 & 0.7 & 133.8 & 8.6 & 40.7 & 95 & 11.6 \\
\hline Mn & 62.94 & 7745.07 & 422.1 & 8.6 & -2.7 & 434 & & 1349.5 & 5.1 & & & \\
\hline Co & 7.21 & 158.38 & 66.4 & 6.8 & 1.0 & 65.7 & 1.8 & 47.1 & 3.9 & 5.5 & 44.7 & 4.6 \\
\hline $\mathrm{Ni}$ & 279.04 & 12918.06 & 35 & 11.7 & 7.6 & 33 & 5.2 & 57.1 & 5.6 & 5.2 & 54.3 & 4.5 \\
\hline $\mathrm{Cu}$ & 46.77 & 4096.80 & 20 & 12.1 & 1.3 & 20 & & 71.5 & 3.0 & 7.3 & 66.6 & 2.0 \\
\hline Ga & 2.74 & 9.51 & 20.0 & 6.3 & -9.2 & 22 & & 22.2 & 2.8 & 1.4 & 21.9 & 4.3 \\
\hline $\mathrm{Zn}$ & 604.18 & 38338.68 & 50 & 17.1 & 4.2 & 48 & & 134.0 & 9.9 & 18.1 & 113.4 & 7.4 \\
\hline
\end{tabular}




\begin{tabular}{|c|c|c|c|c|c|c|c|c|c|c|c|c|c|c|c|c|c|}
\hline \multicolumn{18}{|c|}{ JSd-1 } \\
\hline \multicolumn{3}{|c|}{ Alkaline fusion } & \multicolumn{3}{|c|}{ Method A } & \multicolumn{3}{|c|}{ Method B } & \multicolumn{3}{|c|}{ Method C } & \multicolumn{3}{|c|}{ Method D } & \multicolumn{3}{|c|}{ Method D, 200mg } \\
\hline$M V(n=2)$ & $\%$ RDS & $\Delta(\%)$ & $M V(n=2)$ & $\%$ RDS & $\Delta(\%)$ & $M V(n=4)$ & $\%$ RDS & $\Delta(\%)$ & MV $(n=11$ & $\%$ RDS & $\Delta(\%)$ & $\operatorname{MV}(n=16$ & $\%$ RDS & $\Delta(\%)$ & $M V(n=2)$ & $\%$ RDS & $\Delta(\%)$ \\
\hline & & & 2.1 & 6.7 & 5.3 & 2.2 & 8.0 & 11.8 & 3 & 20.1 & 27.1 & 2.3 & 3.7 & 16.8 & 2.2 & & 11.1 \\
\hline 0 & 33.8 & -99.9 & 63.3 & 3.3 & -2.7 & 46 & 50.4 & -29.1 & 49 & 42.9 & -25.2 & 47 & 22.2 & -27.6 & 50.9 & 4.1 & -21.9 \\
\hline 487.7 & 0.7 & -4.6 & 511.6 & 6.8 & 0.1 & 484.4 & 3.9 & -5.2 & 466 & 10.2 & -8.8 & 483.2 & 7.2 & -5.4 & 478.4 & 3.1 & -6.4 \\
\hline 4.3 & 0.4 & -0.8 & 3.9 & 9.8 & -8.8 & 2 & 21.3 & -51.7 & 3 & 19.6 & -19.7 & 3.9 & 7.8 & -10.3 & 3.7 & 0.1 & -13.8 \\
\hline 0.2 & 0.5 & -81.2 & 1 & 10.0 & 1.2 & 0.6 & 15.2 & -39.9 & 1 & 30.6 & -32.0 & 0.8 & 11.3 & -12.5 & 0.7 & 4.4 & -21.1 \\
\hline 1.9 & 0.6 & -83.3 & 16 & 12.4 & 39.9 & 16.3 & 5.7 & 41.3 & 17 & 49.9 & 44.4 & 16 & 18.9 & 35.1 & 11 & 12.5 & -6.4 \\
\hline 0 & 12.5 & -100.0 & 0.9 & 7.1 & -2.6 & 0.9 & 8.3 & 6.0 & 1 & 57.5 & 11.3 & 0.9 & 11.0 & 5.8 & 0.7 & 14.3 & -24.3 \\
\hline 15.4 & 0.4 & -12.9 & 16.5 & 1.3 & -6.6 & 10 & 19.6 & -45.8 & 13 & 21.7 & -28.0 & 14.2 & 8.1 & -19.7 & 14.8 & 3.6 & -16.3 \\
\hline 30.1 & 0.7 & -11.4 & 31.9 & 1.0 & -6.1 & 24.9 & 9.0 & -26.6 & 27 & 18.5 & -21.1 & 30.3 & 5.1 & -10.7 & 29.9 & 4.8 & -12.0 \\
\hline 4.1 & 1.5 & -69.6 & & & & 25 & 18.2 & 85.0 & 10 & 92.8 & -22.7 & 5.6 & 6.9 & -58.0 & 10.8 & 3.0 & -19.6 \\
\hline 3.9 & 0.9 & -4.5 & 4.0 & 3.9 & -2.4 & 2 & 20.0 & -42.1 & 3 & 16.6 & -19.1 & 3.7 & 6.3 & -8.4 & 3.7 & 5.4 & -8.6 \\
\hline 283.2 & 3.2 & -12.0 & 328.9 & 1.0 & 2.2 & 245 & 36.1 & -24.0 & 269 & 28.0 & -16.3 & 281 & 11.3 & -12.6 & 273.6 & 3.1 & -14.9 \\
\hline 15.6 & 1.1 & -10.3 & 15.9 & 5.7 & -8.5 & 9 & 20.9 & -45.5 & 14 & 16.0 & -22.0 & 15.2 & 4.6 & -12.4 & 14.7 & 4.0 & -15.5 \\
\hline 133.9 & 0.3 & 0.7 & 27.9 & 0.9 & -79.0 & 73 & 39.9 & -44.8 & 75 & 31.9 & -43.6 & 86 & 12.5 & -35.6 & 102.8 & 5.4 & -22.7 \\
\hline 3.2 & 1.0 & -7.3 & 1.0 & 7.6 & -71.9 & 2 & 31.0 & -45.4 & 2 & 29.3 & -41.2 & 2.5 & 9.9 & -27.1 & 2.5 & 0.6 & -28.5 \\
\hline 3.3 & 0.4 & -9.7 & 3.3 & 3.0 & -8.9 & 2 & 21.3 & -43.0 & 3 & 14.0 & -15.9 & 3.4 & 5.6 & -6.9 & 3.1 & 0.8 & -14.4 \\
\hline 0.9 & 1.7 & -4.6 & 0.9 & 2.1 & -1.4 & 0.5 & 23.1 & -41.9 & 0.8 & 12.3 & -11.2 & 0.9 & 5.7 & -4.9 & 0.8 & 3.7 & -9.2 \\
\hline 3.0 & 1.4 & 4.2 & 3.3 & 6.3 & 14.0 & 1.9 & 22.2 & -32.7 & 3 & 10.1 & 1.2 & 3.2 & 5.1 & 12.6 & 2.9 & 9.2 & 1.7 \\
\hline 0.4 & 1.0 & 0.0 & 0.5 & 1.4 & 7.1 & 0.3 & 24.6 & -34.4 & 0.4 & 8.0 & 1.7 & 0.5 & 3.5 & 11.2 & 0.4 & 2.7 & -2.0 \\
\hline 2.5 & 0.4 & 7.1 & 2.4 & 1.3 & 4.8 & 1.5 & 24.5 & -32.9 & 2.4 & 7.8 & 4.2 & 2.5 & 4.3 & 10.8 & 2.3 & 3.7 & 2.2 \\
\hline 14.2 & 0.4 & -6.7 & 14.9 & 3.8 & -2.2 & 8.7 & 26.2 & -42.7 & 14.0 & 9.3 & -7.9 & 14.1 & 4.3 & -7.3 & 13.6 & 7.5 & -11.1 \\
\hline 0.5 & 0.7 & 33.1 & 0.5 & 1.1 & 33.4 & 0.3 & 25.0 & -18.0 & 0.5 & 6.5 & 25.9 & 0.5 & 2.9 & 38.6 & 0.5 & 4.5 & 24.1 \\
\hline 1.3 & 0.5 & 37.5 & 1.4 & 5.5 & 43.7 & 0.8 & 25.5 & -13.4 & 1.3 & 5.1 & 34.7 & 1.4 & 4.4 & 43.4 & 1.3 & 2.9 & 30.9 \\
\hline 1.2 & 0.4 & -1.1 & 1.1 & 2.8 & -10.4 & 0.7 & 25.0 & -40.3 & 1.2 & 5.2 & -5.0 & 1.3 & 3.7 & 0.4 & 1.1 & 1.7 & -11.3 \\
\hline 0.2 & 0.9 & -3.1 & 0.2 & 3.7 & -11.3 & 0.1 & 25.5 & -43.2 & 0.2 & 5.5 & -9.3 & 0.2 & 3.6 & -4.2 & 0.2 & 3.3 & -14.3 \\
\hline 10.1 & 0.7 & -9.1 & 11.6 & 9.3 & 5.1 & 8.1 & 12.5 & -27.2 & 12 & 22.7 & 6.9 & 10.6 & 5.3 & -4.3 & 9.7 & 4.7 & -12.8 \\
\hline 0.6 & 1.4 & -12.0 & 0.7 & 15.1 & 11.2 & & & & & & & 0.7 & 10.7 & 6.7 & 0.6 & 8.9 & -2.3 \\
\hline 0 & 28.8 & -99.9 & 74 & 13.8 & -6.1 & 90.1 & 4.1 & 14.7 & 77.4 & 9.1 & -1.4 & 73 & 11.2 & -7.5 & 73.9 & 3.7 & -5.9 \\
\hline & & & 19 & 11.0 & -14.8 & 22.8 & 21.4 & 0.4 & 21 & 59.9 & -5.8 & 22 & 90.0 & -4.1 & 10.5 & 6.6 & -53.8 \\
\hline 621.3 & 1.1 & & 687.8 & 6.9 & & & & & & & & 733.9 & 4.5 & & 698.0 & 1.4 & \\
\hline 9.3 & 0.5 & -18.3 & 11 & 13.2 & -7.2 & 12.7 & 5.9 & 12.1 & 10 & 19.1 & -10.3 & 11.5 & 5.2 & 1.0 & 10.8 & 0.5 & -4.9 \\
\hline 3.8 & 4.9 & -48.0 & 7.7 & 0.4 & 6.3 & 3.2 & 138.9 & -56.0 & 8 & 28.0 & 5.8 & 11 & 48.8 & 48.7 & 6.6 & 5.6 & -9.2 \\
\hline 9.2 & 1.6 & -59.6 & 24.3 & 3.0 & 6.3 & 29.8 & 2.1 & 30.3 & 24 & 15.8 & 4.4 & 25.3 & 3.9 & 10.9 & 22.1 & 5.3 & -3.2 \\
\hline 0.0 & 7.4 & -99.8 & 16.7 & 3.4 & -1.6 & 18.2 & 0.9 & 7.0 & 15.9 & 9.4 & -6.5 & 17.0 & 3.8 & 0.0 & 16.3 & 2.7 & -4.4 \\
\hline 12.2 & 3.4 & -87.6 & 100.6 & 4.5 & 2.2 & 142.1 & 9.7 & 44.3 & 96 & 17.9 & -2.9 & 97 & 14.3 & -1.6 & 86 & 10.2 & -12.4 \\
\hline
\end{tabular}

1 continued 


\begin{tabular}{|c|c|c|c|c|}
\hline \multicolumn{3}{|c|}{ Method D, 400mg } & \multicolumn{2}{|c|}{ Published } \\
\hline$M V(n=2)$ & $\%$ RDS & $\Delta(\%)$ & $M V(n=3)$ & $\%$ RDS \\
\hline 2.3 & & 14.5 & 2.0 & 4.1 \\
\hline 53.3 & 5.7 & -18.1 & 65.1 & 3.5 \\
\hline 516.4 & 3.2 & 1.0 & 511.0 & 2.5 \\
\hline 3.6 & 1.7 & -15.6 & 4.3 & 4.6 \\
\hline 0.8 & 2.9 & -15.2 & 0.9 & 8.2 \\
\hline 11 & 13.6 & -2.2 & 11.6 & 5.5 \\
\hline 0.7 & 13.6 & -18.7 & 0.9 & \\
\hline 14.5 & 5.2 & -17.7 & 17.7 & 6.8 \\
\hline 30.2 & 4.3 & -11.1 & 33.9 & 5.1 \\
\hline 11.1 & 3.6 & -17.4 & 13.4 & 4.1 \\
\hline 3.8 & 6.2 & -6.7 & 4.1 & 1.4 \\
\hline 282.4 & 7.7 & -12.2 & 321.7 & 5.9 \\
\hline 15.0 & 4.4 & -13.7 & 17.4 & 3.4 \\
\hline 105.4 & 5.4 & -20.7 & 133.0 & 1.1 \\
\hline 2.5 & 0.6 & -28.2 & 3.5 & 3.1 \\
\hline 3.2 & 2.2 & -10.8 & 3.6 & 5.8 \\
\hline 0.9 & 2.3 & -5.9 & 0.9 & 1.1 \\
\hline 3 & 10.1 & 4.1 & 3 & 12.4 \\
\hline 0.4 & 2.7 & 2.4 & 0.4 & 7.0 \\
\hline 2.5 & 2.1 & 7.0 & 2 & 10.3 \\
\hline 14.3 & 8.2 & -6.4 & 15.3 & 4.2 \\
\hline 0.5 & 4.3 & 30.8 & 0.4 & 27.1 \\
\hline 1.3 & 1.7 & 37.7 & 1 & 40.0 \\
\hline 1.2 & 0.9 & -6.7 & 1.3 & 9.2 \\
\hline 0.2 & 4.1 & -8.5 & 0.2 & 8.1 \\
\hline 9.6 & 5.8 & -13.2 & 11.1 & 2.6 \\
\hline 0.6 & 9.7 & -5.4 & 0.6 & 0.8 \\
\hline 71.5 & 3.8 & -8.9 & 78.5 & 4.5 \\
\hline 7.7 & 7.5 & -66.3 & 22.8 & 7.8 \\
\hline 658.1 & 2.7 & & & \\
\hline 10.6 & 0.8 & -6.8 & 11.4 & 5.0 \\
\hline 6.9 & 7.1 & -5.0 & 7.2 & 6.1 \\
\hline 20.8 & 5.7 & -8.8 & 22.8 & 5.6 \\
\hline 16.4 & 4.9 & -3.8 & 17.0 & 1.7 \\
\hline 87.8 & 9.4 & -10.8 & 98.5 & 1.8 \\
\hline
\end{tabular}

\begin{tabular}{|c|c|c|c|c|c|c|c|c|c|c|}
\hline & \multirow{2}{*}{\multicolumn{3}{|c|}{ Method A }} & & & & & & & \multirow{3}{*}{$\begin{array}{r}\text { JSc } \\
I\end{array}$} \\
\hline & & & & \multicolumn{3}{|c|}{ Method B } & \multicolumn{3}{|c|}{ Method C } & \\
\hline & $M V(n=2)$ & $\%$ RDS & $\Delta(\%)$ & $M V(n=6)$ & $\%$ RDS & $\Delta(\%)$ & $M V(n=2)$ & $\%$ RDS & $\Delta(\%)$ & \\
\hline Cs & 1.1 & 5.9 & 2.8 & 1.2 & 6.7 & 6.5 & 1.2 & 0.1 & 7.0 & 1.2 \\
\hline $\mathbf{R b}$ & 26.3 & 5.6 & -0.4 & 23 & 22.6 & -14.0 & 24.9 & 1.2 & -5.7 & 24.5 \\
\hline $\mathrm{Ba}$ & 1316 & 14.7 & 7.7 & 1113.1 & 8.2 & -8.9 & 1166.5 & 4.4 & -4.5 & 1227.8 \\
\hline Th & 2 & 13.9 & 2.2 & 2 & 27.9 & -30.4 & 2.3 & 1.5 & -6.7 & 2.4 \\
\hline $\mathbf{U}$ & 1.1 & 5.8 & -5.5 & 1.0 & 5.6 & -10.8 & 1.0 & 7.1 & -10.4 & 1.1 \\
\hline $\mathrm{Nb}$ & 7 & 20.9 & 52.9 & 6 & 12.7 & 25.3 & 9 & 80.2 & 90.4 & 5 \\
\hline $\mathrm{Ta}$ & 0.5 & 21.0 & -6.9 & 0.4 & 11.5 & -27.3 & 0.7 & 51.4 & 39.3 & 0.4 \\
\hline La & 11 & 11.2 & -1.3 & 8 & 21.6 & -30.1 & 10.3 & 5.0 & -8.9 & 10.2 \\
\hline $\mathrm{Ce}$ & 22 & 13.0 & -1.2 & 19.5 & 5.7 & -12.5 & 21.6 & 3.4 & -2.8 & 21.3 \\
\hline $\mathbf{P b}$ & & & & 50.9 & 1.1 & -66.5 & 49.6 & & -67.4 & 177 \\
\hline $\mathrm{Pr}$ & 3 & 11.7 & 13.1 & 2 & 21.5 & -17.4 & 2.7 & 4.6 & 6.6 & 2.9 \\
\hline $\mathrm{Sr}$ & 211 & 10.2 & 6.2 & 214.2 & 2.6 & 7.6 & 216.0 & 4.1 & 8.6 & 201.5 \\
\hline Nd & 12 & 13.0 & -7.2 & 9 & 20.9 & -28.1 & 11.6 & 3.1 & -8.4 & 11.6 \\
\hline $\mathrm{Zr}$ & 77 & 39.9 & -24.8 & 99.8 & 3.5 & -2.3 & 99.5 & 6.4 & -2.7 & 101.9 \\
\hline Hf & 2 & 43.5 & -28.0 & 2.5 & 4.2 & -5.2 & 3 & 15.5 & -3.5 & 2.6 \\
\hline Sm & 3.0 & 9.5 & 8.8 & 2 & 21.0 & -19.0 & 2.8 & 1.2 & 3.2 & 2.8 \\
\hline Eu & 0.7 & 5.6 & -13.8 & 0.6 & 19.7 & -23.9 & 0.9 & 18.5 & 8.1 & 0.8 \\
\hline Gd & 3.3 & 6.6 & 18.5 & 2 & 23.5 & -14.6 & 2.9 & 2.8 & 2.7 & 3.0 \\
\hline Tb & 0.5 & 6.5 & 9.5 & 0.4 & 22.7 & -12.2 & 0.5 & 1.0 & 5.1 & 0.5 \\
\hline Dy & 2.8 & 7.1 & -2.2 & 2 & 21.7 & -17.5 & 2.9 & 0.1 & 2.2 & 3.0 \\
\hline$Y$ & 19 & 13.1 & 10.1 & 15 & 22.2 & -12.2 & 18.1 & 6.6 & 7.5 & 18.6 \\
\hline Ho & 0.6 & 7.1 & -3.9 & 0.5 & 21.5 & -21.3 & 0.6 & 0.8 & -4.3 & 0.6 \\
\hline $\mathrm{Er}$ & 1.9 & 9.7 & 19.9 & 1 & 21.6 & -4.9 & 1.8 & 2.0 & 17.2 & 1.9 \\
\hline $\mathrm{Yb}$ & 2 & 19.9 & -2.8 & 1 & 22.4 & -14.9 & 1.8 & 2.7 & 4.5 & 1.8 \\
\hline Lu & 0.2 & 15.8 & -8.5 & 0.2 & 22.8 & -14.7 & 0.3 & 3.8 & 5.0 & 0.3 \\
\hline Sc & 19.7 & 6.5 & 14.4 & 15 & 18.1 & -11.8 & 19 & 12.3 & 9.1 & 18.1 \\
\hline $\mathrm{Ti}$ & 0.7 & 8.2 & 19.2 & & & & & & & 0.6 \\
\hline V & 146.8 & 5.2 & 17.9 & 144 & 10.9 & 15.5 & 128.0 & 8.3 & 2.8 & 122 \\
\hline $\mathrm{Cr}$ & 134 & 28.9 & 28.2 & 94 & 25.7 & -10.5 & 86 & 81.4 & -17.4 & 87 \\
\hline Mn & 1005.7 & 5.1 & & & & & & & & 893.0 \\
\hline Co & 54.2 & 8.6 & 12.0 & 46 & 16.2 & -5.8 & 52 & 14.1 & 6.8 & 47.7 \\
\hline $\mathrm{Ni}$ & 108 & 15.3 & 16.7 & 80 & 29.2 & -14.4 & 96 & 15.1 & 3.4 & 92.1 \\
\hline $\mathrm{Cu}$ & 1298 & 13.5 & 15.8 & 1224 & 14.1 & 9.3 & 1301.6 & 3.9 & 16.2 & 1037.7 \\
\hline $\mathbf{G a}$ & 14.7 & 9.1 & -0.7 & 14.3 & 4.0 & -3.4 & 14.6 & 7.6 & -0.9 & 13.0 \\
\hline $\mathrm{Zn}$ & 2411 & 14.5 & 17.9 & 2424 & 21.5 & 18.5 & 2136.3 & 1.9 & 4.4 & 1790 \\
\hline
\end{tabular}

Table 1 continued 


\begin{tabular}{|c|c|c|c|c|c|c|c|c|c|}
\hline \multicolumn{10}{|l|}{$y-2$} \\
\hline \multicolumn{2}{|l|}{ Method D } & \multicolumn{3}{|c|}{ Method D, 200mg } & \multicolumn{3}{|c|}{ Method D, 400mg } & \multicolumn{2}{|c|}{ Published } \\
\hline \%RDS & $\Delta(\%)$ & $M V(n=2)$ & $\%$ RDS & $\Delta(\%)$ & $M V(n=2)$ & $\%$ RDS & $\Delta(\%)$ & $M V(n=5)$ & $\%$ RDS \\
\hline 9.7 & 6.6 & 2 & 34.0 & 64.5 & 2 & 33.4 & 57.3 & 1.1 & 6.8 \\
\hline 4.6 & -7.0 & 25.7 & 1.7 & -2.6 & 24.3 & 3.4 & -8.0 & 26.4 & 3.1 \\
\hline 2.3 & 0.5 & 1227.9 & 1.4 & 0.5 & 1137.4 & 3.6 & -6.9 & 1221.3 & 5.4 \\
\hline 6.8 & -2.5 & 2.3 & 0.2 & -6.9 & 2.4 & 1.2 & -3.4 & 2.4 & 6.6 \\
\hline 8.2 & -5.8 & 1.0 & 0.3 & -10.6 & 1.1 & 1.7 & -9.0 & 1.2 & 9.4 \\
\hline 11.7 & 6.3 & 4 & 10.5 & -12.2 & 4 & 11.5 & -11.8 & 4.5 & 2.5 \\
\hline 13.7 & -21.4 & 0.3 & 14.8 & -41.1 & 0.3 & 18.6 & -42.3 & 0.5 & \\
\hline 6.4 & -9.4 & 10.6 & 1.2 & -6.3 & 10.7 & 3.4 & -5.1 & 11.3 & 5.5 \\
\hline 5.4 & -4.2 & 21.2 & 1.8 & -4.7 & 21.9 & 3.1 & -1.7 & 22.2 & 4.9 \\
\hline 33.4 & 16.3 & 132.9 & 3.7 & -12.6 & 132.8 & 8.7 & -12.7 & 152.0 & 3.5 \\
\hline 4.5 & 10.6 & 2.8 & 2.7 & 10.4 & 2.9 & 4.6 & 12.6 & 3 & 14.1 \\
\hline 5.0 & 1.3 & 203.5 & 2.2 & 2.2 & 200.0 & 3.4 & 0.5 & 199.0 & 6.8 \\
\hline 6.9 & -8.2 & 11.9 & 2.5 & -6.2 & 12.0 & 4.6 & -5.3 & 12.7 & 4.4 \\
\hline 7.2 & -0.3 & 102.9 & 2.5 & 0.7 & 99.4 & 3.6 & -2.7 & 102.2 & 8.3 \\
\hline 9.0 & -0.6 & 2.4 & 1.4 & -7.3 & 2.4 & 2.5 & -10.0 & 2.6 & 7.5 \\
\hline 2.5 & 3.3 & 2.8 & 1.2 & 2.3 & 2.8 & 3.0 & 2.2 & 2.8 & 7.6 \\
\hline 6.5 & -2.4 & 0.9 & 2.3 & 1.7 & 0.9 & 4.6 & 1.0 & 0.9 & 6.1 \\
\hline 6.8 & 6.8 & 2.9 & 6.9 & 3.6 & 2.9 & 8.4 & 4.7 & 2.8 & 7.3 \\
\hline 4.6 & 8.9 & 0.5 & 1.4 & 7.1 & 0.5 & 3.9 & 8.0 & 0.4 & 7.8 \\
\hline 2.5 & 5.9 & 3.0 & 1.4 & 4.8 & 3.0 & 3.2 & 4.8 & 2.9 & 4.9 \\
\hline 7.0 & 10.3 & 19.2 & 3.7 & 13.6 & 18.6 & 5.7 & 10.4 & 16.9 & 4.4 \\
\hline 7.1 & 1.2 & 0.6 & 2.4 & -0.4 & 0.6 & 3.7 & -0.6 & 0.6 & 7.1 \\
\hline 3.0 & 24.1 & 1.9 & 1.9 & 20.2 & 1.9 & 2.4 & 19.1 & 2 & 16.7 \\
\hline 7.0 & 6.6 & 1.8 & 2.9 & 6.2 & 1.8 & 4.1 & 4.8 & 1.7 & 8.4 \\
\hline 2.9 & 13.2 & 0.3 & 3.4 & 6.5 & 0.3 & 5.6 & 6.3 & 0.3 & 14.4 \\
\hline 5.3 & 5.2 & 18.9 & 1.1 & 10.0 & 18.3 & 3.1 & 6.6 & 17.2 & 2.1 \\
\hline 6.5 & -4.8 & 0.6 & 4.6 & -9.0 & 0.6 & 5.1 & -7.9 & 0.6 & 1.8 \\
\hline 11.9 & -1.7 & 126.3 & 0.8 & 1.4 & 121.0 & 1.8 & -2.8 & 124.5 & 0.6 \\
\hline 40.9 & -16.9 & 67.7 & 4.3 & -35.3 & 60.5 & 2.7 & -42.2 & 104.7 & 2.9 \\
\hline 2.8 & & 899.9 & 0.5 & & 870.3 & 0.7 & & & \\
\hline 3.0 & -1.6 & 48.7 & 0.5 & 0.5 & 46.5 & 0.9 & -4.0 & 48.4 & 0.9 \\
\hline 5.8 & -0.9 & 92.2 & 1.4 & -0.8 & 86.8 & 3.6 & -6.5 & 92.9 & 1.1 \\
\hline 9.4 & -7.4 & 1062.9 & 4.7 & -5.1 & 970.6 & 6.8 & -13.4 & 1120.3 & 0.8 \\
\hline 6.5 & -11.9 & 13.4 & 0.9 & -9.2 & 13.1 & 1.1 & -11.2 & 14.8 & 5.3 \\
\hline 13.1 & -12.5 & 1842.6 & 9.0 & -9.9 & 1701.1 & 8.7 & -16.8 & 2045.3 & 1.5 \\
\hline
\end{tabular}

\begin{tabular}{|c|c|c|c|c|c|}
\hline \multirow[b]{3}{*}{ Cs } & \multicolumn{3}{|c|}{ Method A } & \multicolumn{2}{|r|}{ Method B } \\
\hline & $M V(n=2)$ & $\%$ RDS & $\Delta(\%)$ & $M V(n=3)$ & $\%$ RDS \\
\hline & \begin{tabular}{|l|}
34.0 \\
\end{tabular} & 5.7 & 11.7 & 25 & 13.1 \\
\hline $\mathbf{R b}$ & 274.0 & 3.0 & -0.8 & 37 & 31.3 \\
\hline $\mathrm{Ba}$ & 441.0 & 5.0 & -1.1 & 224.0 & 9.9 \\
\hline Th & 6.8 & 0.6 & -7.6 & 1.6 & 4.6 \\
\hline $\mathbf{U}$ & 1.4 & 9.7 & -11.3 & 0.9 & 8.1 \\
\hline $\mathrm{Nb}$ & 13.0 & 3.9 & 66.3 & 9.8 & 4.1 \\
\hline $\mathrm{Ta}$ & 0.8 & 6.5 & 10.4 & 0.5 & 5.5 \\
\hline La & 18.7 & 6.9 & -6.7 & 4 & 12.3 \\
\hline $\begin{array}{l}\mathrm{Ce} \\
\mathrm{Pb}\end{array}$ & 40.0 & 1.5 & -5.0 & 30 & 11.7 \\
\hline Pr & 4.1 & 0.3 & 6.9 & 1.1 & 6.8 \\
\hline $\mathrm{Sr}$ & 56.9 & 2.1 & 2.1 & 15 & 26.1 \\
\hline Nd & 15.1 & 6.2 & -7.3 & 4.7 & 9.8 \\
\hline $\mathrm{Zr}$ & 82.4 & 9.5 & -34.8 & 108.3 & 4.2 \\
\hline Hf & 2.1 & 7.3 & -34.8 & 2.7 & 2.9 \\
\hline Sm & 3.2 & 5.1 & -4.9 & 1 & 15.8 \\
\hline Eu & 0.7 & 0.9 & -5.1 & 0.3 & 23.8 \\
\hline Gd & 2.8 & 0.6 & 1.1 & 1 & 17.6 \\
\hline Tb & 0.4 & 5.1 & 23.0 & 0.2 & 17.4 \\
\hline Dy & 2.4 & 0.0 & 5.6 & 1 & 17.1 \\
\hline $\mathbf{Y}$ & 13.8 & 4.3 & -0.7 & 9 & 14.0 \\
\hline Ho & 0.5 & 2.7 & 2.1 & 0.3 & 16.5 \\
\hline $\mathrm{Er}$ & 1.5 & 3.8 & 33.7 & 0.9 & 15.1 \\
\hline$Y \mathbf{b}$ & 1.3 & 5.3 & 2.1 & 1 & 12.4 \\
\hline Lu & 0.2 & 3.8 & 3.7 & 0.2 & 12.0 \\
\hline Sc & 11.3 & 2.4 & 7.0 & 4 & 21.4 \\
\hline $\mathrm{Ti}$ & 0.5 & 3.8 & 17.4 & & \\
\hline V & 79.8 & 0.1 & 12.1 & 78.1 & 5.2 \\
\hline $\mathrm{Cr}$ & 47 & 29.1 & 30.1 & 31.1 & 6.4 \\
\hline Mn & 1126.5 & 0.3 & & & \\
\hline Co & 12.9 & 4.7 & 3.8 & 12.0 & 3.9 \\
\hline $\mathrm{Ni}$ & 19.9 & 4.3 & 2.7 & 15 & 29.1 \\
\hline $\mathrm{Cu}$ & 459.9 & 4.5 & 8.8 & 511.7 & 1.4 \\
\hline Ga & 13.1 & 5.8 & -2.9 & 13.6 & 2.1 \\
\hline $\mathrm{Zn}$ & 151.3 & 1.8 & 10.7 & 148.0 & 7.8 \\
\hline
\end{tabular}

Table 1 continued 


\begin{tabular}{|c|c|c|c|c|c|c|c|c|c|c|c|c|c|c|}
\hline & & & & JSO & $1-3$ & & & & & & & & & \\
\hline 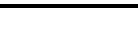 & & lethod C & & & Method D & & Meth & od $D, 20$ & $m g$ & Meth & od $D, 40$ & $m g$ & Publis & hed \\
\hline$\Delta(\%)$ & $M V(n=2)$ & $\%$ RDS & $\Delta(\%)$ & $M V(n=6)$ & $\%$ RDS & $\Delta(\%)$ & $M V(n=2)$ & $\%$ RDS & $\Delta(\%)$ & $M V(n=2)$ & $\%$ RDS & $\Delta(\%)$ & $M V(n=3)$ & $\%$ RDS \\
\hline-17.6 & 35.1 & 2.3 & 15.3 & 39 & 24.7 & 29.0 & 41 & 35.3 & 35.5 & 40 & 27.3 & 30.3 & 30.4 & 0.9 \\
\hline-86.8 & 218 & 22.1 & -21.2 & 236.8 & 8.9 & -14.3 & 200.2 & 3.3 & -27.6 & 216.6 & 0.4 & -21.6 & 276.3 & 5.4 \\
\hline-49.8 & 402.6 & 8.3 & -9.7 & 419.7 & 4.2 & -5.9 & 364.0 & 4.3 & -18.4 & 408.6 & 0.7 & -8.4 & 446.0 & 5.1 \\
\hline-78.1 & 5.9 & 7.3 & -18.9 & 6.4 & 8.3 & -12.6 & 5.2 & 1.6 & -28.4 & 5.7 & 0.5 & -22.1 & 7.3 & 9.2 \\
\hline-43.1 & 1.4 & 2.9 & -10.0 & 1.6 & 8.3 & -0.8 & 1.3 & 0.5 & -20.7 & 1.4 & 0.3 & -14.6 & 1.6 & 6.7 \\
\hline 26.1 & 16 & 61.8 & 104.0 & 9 & 15.5 & 14.2 & 6.7 & 13.2 & -13.8 & 7.4 & 8.8 & -4.5 & 7.8 & \\
\hline-28.5 & 1 & 51.5 & 8.2 & 0.6 & 6.4 & -17.3 & 0.4 & 20.6 & -39.9 & 0.5 & 14.8 & -27.5 & 0.7 & \\
\hline-79.8 & 15 & 18.4 & -23.7 & 17.5 & 4.5 & -12.5 & 15.1 & 5.0 & -24.5 & 16.3 & 1.7 & -18.7 & 20.0 & 1.0 \\
\hline-27.9 & 39.3 & 1.3 & -6.4 & 39.1 & 5.4 & -6.9 & 34.2 & 5.7 & -18.6 & 36.5 & 2.0 & -13.2 & 42.0 & 1.5 \\
\hline & 25.7 & & -68.7 & 64 & 30.9 & -22.1 & 65.9 & 6.7 & -20.0 & 67.3 & 5.8 & -18.2 & 82.3 & 0.5 \\
\hline-70.2 & 4 & 21.4 & -7.9 & 4.1 & 3.5 & 5.9 & 3.5 & 5.7 & -8.7 & 3.9 & 3.2 & 1.0 & 4 & 19.7 \\
\hline-73.9 & 55.6 & 9.5 & -0.2 & 50 & 10.0 & -10.2 & 44.2 & 5.4 & -20.7 & 48.9 & 0.9 & -12.2 & 56 & 11.4 \\
\hline-71.3 & 13 & 22.5 & -18.0 & 14.8 & 3.8 & -8.6 & 12.8 & 5.5 & -20.9 & 14.2 & 3.1 & -12.4 & 16.2 & 2.8 \\
\hline-14.4 & 112 & 21.5 & -11.1 & 114.4 & 6.8 & -9.6 & 109.3 & 4.7 & -13.6 & 115.8 & 2.4 & -8.4 & 126.5 & 2.8 \\
\hline-14.7 & 3 & 21.9 & -11.3 & 3.1 & 7.8 & -2.3 & 2.7 & 2.5 & -16.2 & 2.9 & 2.4 & -10.6 & 3.2 & 0.2 \\
\hline-65.6 & 3 & 21.3 & -19.8 & 3.0 & 4.4 & -13.0 & 2.5 & 2.5 & -25.3 & 2.8 & 0.6 & -16.8 & 3.4 & 7.7 \\
\hline-62.7 & 0.6 & 10.2 & -14.3 & 0.6 & 6.2 & -7.6 & 0.5 & 4.5 & -22.1 & 0.6 & 3.0 & -10.0 & 0.7 & 2.2 \\
\hline-57.1 & 3 & 18.1 & -10.4 & 2.7 & 7.2 & -3.9 & 2 & 10.6 & -16.6 & 2.7 & 7.5 & -4.6 & 2.8 & 6.1 \\
\hline-42.3 & 0.4 & 13.6 & 6.6 & 0.4 & 4.8 & 11.7 & 0.3 & 3.6 & -6.3 & 0.4 & 0.6 & 8.8 & 0.4 & 15.4 \\
\hline-42.6 & 2.2 & 8.0 & -2.4 & 2.3 & 3.4 & 4.3 & 1.9 & 2.0 & -13.6 & 2.3 & 0.8 & 2.1 & 2.2 & 1.4 \\
\hline-33.2 & 13.3 & 9.3 & -4.0 & 13.2 & 7.5 & -4.8 & 11.4 & 6.6 & -17.9 & 13.4 & 3.3 & -3.7 & 14 & 10.2 \\
\hline-40.0 & 0.4 & 6.6 & -4.5 & 0.5 & 5.1 & 3.6 & 0.4 & 2.8 & -16.4 & 0.5 & 3.0 & 0.9 & 0.5 & 7.3 \\
\hline-18.6 & 1.4 & 7.0 & 24.5 & 1.4 & 6.3 & 31.1 & 1.1 & 3.3 & 3.8 & 1.4 & 1.7 & 24.9 & 1 & 18.4 \\
\hline-20.6 & 1.4 & 2.3 & 5.0 & 1.5 & 4.7 & 11.9 & 1.1 & 5.1 & -13.7 & 1.4 & 4.8 & 5.3 & 1.3 & 7.3 \\
\hline-20.0 & 0.2 & 2.5 & 3.7 & 0.2 & 3.2 & 9.2 & 0.2 & 6.2 & -15.1 & 0.2 & 6.8 & 4.6 & 0.2 & 2.6 \\
\hline-60.6 & 9.8 & 25.1 & -6.7 & 10.1 & 9.6 & -4.0 & 8.2 & 3.8 & -22.6 & 9.9 & 0.5 & -6.3 & 10.5 & 2.4 \\
\hline-100.0 & & & & 0.4 & 10.0 & -3.8 & 0.4 & 4.7 & -11.2 & 0.4 & 3.1 & -7.7 & 0.4 & 2.9 \\
\hline 9.7 & 63 & 26.9 & -12.1 & 67 & 10.8 & -5.5 & 67.1 & 1.0 & -5.8 & 68.1 & 0.3 & -4.3 & 71.2 & 1.6 \\
\hline-13.2 & 20 & 113.3 & -44.8 & 31 & 25.6 & -13.1 & 56.6 & 4.6 & 57.8 & 20.8 & 2.3 & -42.1 & 35.9 & 3.5 \\
\hline & & & & 1023 & 11.8 & & 991.4 & 0.6 & & 1016.5 & 0.7 & & & \\
\hline-3.0 & 13.1 & 7.1 & 5.6 & 12 & 11.2 & -7.1 & 11.4 & 0.2 & -7.8 & 11.8 & 0.8 & -4.5 & 12.4 & 2.9 \\
\hline-20.7 & 19 & 13.5 & -4.1 & 19 & 13.2 & -0.2 & 18.9 & 2.2 & -2.2 & 18.0 & 1.1 & -7.0 & 19.4 & 2.1 \\
\hline 21.1 & 507.2 & 0.4 & 20.0 & 391 & 16.2 & -7.4 & 393.1 & 8.0 & -7.0 & 386.4 & 9.5 & -8.6 & 422.7 & 1.4 \\
\hline 1.3 & 13.5 & 0.1 & 0.7 & 12 & 10.5 & -8.2 & 12.2 & 1.4 & -9.2 & 12.6 & 1.6 & -6.0 & 13.5 & 0.5 \\
\hline 8.3 & 139.9 & 0.7 & 2.4 & 132 & 19.35 & -3.5 & 120 & 11.0 & -12.3 & 123 & 13.7 & -10.4 & 136.7 & 1.5 \\
\hline
\end{tabular}




\begin{tabular}{|c|c|c|c|c|c|c|c|c|c|c|c|c|c|c|c|c|c|}
\hline \multicolumn{18}{|c|}{ Jlk-1 } \\
\hline \multicolumn{3}{|c|}{ Alkaline fusion } & \multicolumn{3}{|c|}{ Method B } & \multicolumn{3}{|c|}{ Method C } & \multicolumn{3}{|c|}{ Method D } & \multicolumn{3}{|c|}{ Method D, 200mg } & \multicolumn{3}{|c|}{ Method D, 400mg } \\
\hline$M V(n=2)$ & $\%$ RDS & $\Delta(\%)$ & MV $(n=3)$ & $\%$ RDS & $\Delta(\%)$ & $\operatorname{MV}(n=14$ & $\%$ RDS & $\Delta(\%)$ & $M V(n=8)$ & $\%$ RDS & $\Delta(\%)$ & $M V(n=2)$ & $\%$ RDS & $\Delta(\%)$ & $M V(n=2)$ & $\%$ RDS & $\Delta(\%)$ \\
\hline 0 & 11.4 & -99.6 & 6.3 & 1.0 & -47.4 & 13 & 29.3 & 9.4 & 14 & 12.8 & 18.1 & 15 & 21.8 & 23.9 & 15 & 16.0 & 21.3 \\
\hline 0.4 & 0.6 & -99.7 & 7.3 & 3.6 & -94.8 & 72 & 80.6 & -49.1 & 112 & 13.5 & -20.0 & 98.6 & 1.8 & -29.9 & 109.4 & 1.8 & -22.1 \\
\hline 550.6 & 1.0 & -1.4 & 398.9 & 2.6 & -28.6 & 438 & 19.4 & -21.5 & 497.1 & 5.9 & -11.0 & 469.4 & 1.9 & -16.0 & 510.7 & 1.9 & -8.6 \\
\hline 18.0 & 1.1 & -6.3 & 4.1 & 7.0 & -78.9 & 9 & 68.7 & -52.5 & 14.6 & 9.2 & -24.2 & 13.8 & 1.9 & -28.3 & 14.9 & 2.1 & -22.3 \\
\hline 0.3 & 0.8 & -91.6 & 1.7 & 1.9 & -54.8 & 2 & 50.4 & -44.9 & 3.2 & 7.2 & -14.1 & 3.0 & 0.6 & -20.9 & 3.1 & 0.3 & -17.1 \\
\hline \multirow[t]{2}{*}{4.0} & 3.0 & -75.7 & 16.4 & 5.1 & -0.2 & 22 & 57.4 & 33.5 & 20 & 36.9 & 19.1 & 14 & 11.5 & -15.5 & 14.6 & 8.7 & -11.5 \\
\hline & 5.7 & & 1 & 11.0 & -27.5 & 2 & 66.7 & 2.9 & 1 & 25.5 & -15.6 & 1 & 15.3 & -36.8 & 1 & 13.7 & -31.2 \\
\hline 39.9 & 0.8 & -0.8 & 8 & 19.5 & -81.0 & 17 & 75.5 & -58.2 & 31.9 & 9.0 & -20.8 & 29.8 & 1.2 & -25.9 & 33.1 & 1.2 & -17.7 \\
\hline 80.6 & 0.7 & -7.4 & 20 & 11.5 & -77.5 & 57 & 34.8 & -34.8 & 74.5 & 5.9 & -14.4 & 70.1 & 2.5 & -19.4 & 73.4 & 1.5 & -15.7 \\
\hline 24.4 & 1.0 & -44.8 & 3.7 & 5.2 & -91.7 & 9 & 42.4 & -79.9 & 29 & 25.0 & -35.6 & 33.4 & 3.5 & -24.5 & 32.6 & 4.2 & -26.3 \\
\hline 9.1 & 0.7 & 3.5 & 3 & 12.1 & -70.0 & 4 & 64.9 & -50.0 & 7.5 & 9.9 & -14.9 & 7.3 & 4.2 & -17.7 & 7.9 & 2.7 & -10.4 \\
\hline 61.9 & 1.0 & -6.3 & 8 & 13.7 & -87.4 & 33 & 68.5 & -50.3 & 57.8 & 9.0 & -12.6 & 53.3 & 1.6 & -19.4 & 58.7 & 1.6 & -11.2 \\
\hline 34.5 & 0.8 & -2.6 & 11.3 & 9.7 & -68.0 & 17 & 59.7 & -51.1 & 29 & 10.6 & -18.7 & 27.6 & 3.7 & -22.3 & 30.4 & 3.3 & -14.3 \\
\hline 123.1 & 0.7 & -9.0 & 123.8 & 4.3 & -8.6 & 132.6 & 8.0 & -2.0 & 143 & 14.0 & 5.7 & 134.8 & 4.9 & -0.4 & 127.8 & 5.1 & -5.5 \\
\hline 3.3 & 0.6 & -9.8 & 3.4 & 4.2 & -9.3 & 4 & 10.8 & 0.8 & 4 & 15.6 & 3.3 & 3.4 & 3.2 & -7.2 & 3.3 & 2.0 & -10.4 \\
\hline 7.3 & 1.2 & -3.1 & 3.3 & 6.5 & -56.7 & 4 & 51.1 & -44.2 & 6.3 & 8.4 & -17.1 & 6.0 & 0.6 & -20.5 & 6.6 & 1.6 & -13.1 \\
\hline 1.2 & 1.8 & -2.3 & 0.6 & 5.7 & -52.4 & 0.7 & 48.3 & -42.3 & 1 & 11.9 & -16.3 & 1.0 & 3.2 & -19.1 & 1.1 & 3.0 & -11.8 \\
\hline 7.1 & 1.1 & 13.2 & 3.9 & 3.9 & -36.9 & 5 & 44.7 & -26.0 & 6 & 10.2 & -1.2 & 6.0 & 8.7 & -4.5 & 6.5 & 9.6 & 4.4 \\
\hline 1.1 & 0.7 & -4.8 & 0.7 & 4.0 & -38.7 & 0.8 & 39.7 & -32.9 & 1.0 & 9.0 & -12.1 & 1.0 & 2.5 & -16.7 & 1.1 & 2.6 & -9.1 \\
\hline 6.8 & 0.5 & 4.7 & 4.5 & 3.8 & -30.5 & 5 & 36.2 & -28.1 & 6 & 11.1 & -6.9 & 5.9 & 2.1 & -8.3 & 6.4 & 3.0 & -0.9 \\
\hline 43.9 & 0.2 & 14.9 & 29.4 & 3.8 & -22.9 & 31 & 35.1 & -19.5 & 38.3 & 9.0 & 0.2 & 38.5 & 5.3 & 1.0 & 40.7 & 4.7 & 6.6 \\
\hline 1.4 & 0.1 & 15.7 & 1.0 & 3.2 & -19.6 & 1 & 33.7 & -19.8 & 1.2 & 9.4 & 0.3 & 1.2 & 4.5 & 2.1 & 1.3 & 4.3 & 9.3 \\
\hline 3.9 & 0.2 & 9.2 & 3.0 & 3.5 & -18.1 & 3 & 31.8 & -20.3 & 3.5 & 8.9 & -2.3 & 3.5 & 2.4 & -1.8 & 3.8 & 3.4 & 6.2 \\
\hline 3.8 & 0.1 & -0.3 & 3.0 & 2.3 & -20.7 & 3 & 27.9 & -25.0 & 3.3 & 6.4 & -12.8 & 3.3 & 4.8 & -13.0 & 3.5 & 3.0 & -8.9 \\
\hline 0.5 & 1.0 & -3.0 & 0.4 & 2.5 & -21.2 & 0.4 & 27.0 & -26.5 & 0.5 & 10.7 & -16.7 & 0.5 & 5.9 & -14.4 & 0.5 & 6.5 & -8.7 \\
\hline 13.8 & 9.8 & -13.8 & 5.7 & 3.1 & -64.3 & 11 & 55.8 & -33.4 & 13.9 & 7.2 & -13.5 & 13.8 & 1.7 & -14.3 & 14.0 & 1.9 & -13.2 \\
\hline 1 & 13.9 & -15.4 & & & & & & & 1 & 18.4 & 6.6 & 0.6 & 5.7 & -7.5 & 0.6 & 7.2 & -8.2 \\
\hline \multirow[t]{2}{*}{0} & 76.6 & -99.9 & 106.8 & 3.2 & -8.3 & 107.6 & 5.6 & -7.6 & 115 & 11.6 & -1.1 & 108.3 & 2.2 & -7.0 & 106.2 & 2.1 & -8.9 \\
\hline & 2.2 & & 41 & 26.5 & -41.4 & 68 & 36.5 & -3.2 & 49 & 23.3 & -30.3 & 39.4 & 2.7 & -44.3 & 42.2 & 4.1 & -40.2 \\
\hline 1507 & 23.9 & -22.5 & & & & & & & 1932 & 11.4 & -0.7 & 1805.5 & 1.8 & -7.2 & 1817.4 & 0.4 & -6.6 \\
\hline 12 & 53.1 & -34.5 & 9.2 & 6.7 & -48.4 & 14 & 20.3 & -22.5 & 18 & 12.8 & 0.0 & 16.9 & 0.1 & -5.7 & 16.6 & 0.7 & -7.3 \\
\hline 39.0 & 0.6 & 6.8 & 16.1 & 0.0 & -56.0 & 31 & 12.8 & -14.9 & 37 & 11.8 & 2.0 & 35.6 & 1.4 & -2.5 & 33.6 & 4.5 & -8.0 \\
\hline 25.3 & 4.6 & -60.2 & 57.7 & 8.6 & -9.5 & 62 & 10.1 & -2.6 & 66 & 19.1 & 4.2 & 59.9 & 9.4 & -6.0 & 56 & 10.3 & -12.4 \\
\hline 0.1 & 2.2 & -99.8 & 20.4 & 3.5 & -11.4 & 20.7 & 7.1 & -10.1 & 23.0 & 9.4 & 0.1 & 21.8 & 0.2 & -5.2 & 21.7 & 1.6 & -5.6 \\
\hline 25.3 & 4.5 & -83.3 & 106 & 17.2 & -30.2 & 107 & 26.8 & -29.6 & 217 & 66.0 & 43.2 & 132 & 13.7 & -13.0 & 123.6 & 13.6 & -18.4 \\
\hline
\end{tabular}

1 continued 


\begin{tabular}{|cc|}
\hline \multicolumn{2}{|c|}{ Published } \\
$\mathrm{MV}(\mathrm{n}=5)$ & $\% \mathrm{RDS}$ \\
\hline 12.0 & 6.0 \\
140.5 & 4.2 \\
558.7 & 4.1 \\
19.2 & 4.4 \\
3.8 & 3.7 \\
16.5 & 5.6 \\
1.6 & \\
40.2 & 1.9 \\
87.0 & 2.8 \\
44.3 & 1.3 \\
8.8 & 5.7 \\
66.1 & 6.4 \\
35.4 & 1.3 \\
135.3 & 8.6 \\
3.7 & 7.4 \\
7.6 & 5.3 \\
1.2 & 6.5 \\
6.2 & 9.1 \\
1.2 & 8.1 \\
6.4 & 2.9 \\
38.2 & 6.8 \\
1 & 10.5 \\
3.6 & 2.9 \\
3.8 & 7.8 \\
0.6 & 9.1 \\
16.1 & 1.3 \\
0.7 & 0.2 \\
116.5 & 0.6 \\
70.6 & 3.9 \\
1945 & 10.5 \\
17.9 & 2.3 \\
36.6 & 2.9 \\
63.7 & 6.1 \\
23.0 & 9.8 \\
151.5 & 0.4 \\
\hline &
\end{tabular}

\begin{tabular}{|c|c|c|c|c|c|c|c|c|c|c|c|c|c|c|}
\hline & & & & & & & & & & LKSD-1 & & & & \\
\hline & Met & $d A$ & & Method B & & & Method C & & & Method D & & Meth & od $D, 20$ & $m g$ \\
\hline & $n=1$ & $\Delta(\%)$ & $M V(n=2)$ & $\%$ RDS & $\Delta(\%)$ & $M V(n=4)$ & $\%$ RDS & $\Delta(\%)$ & $M V(n=4)$ & $\%$ RDS & $\Delta(\%)$ & $M V(n=2)$ & $\%$ RDS & $\Delta(\%)$ \\
\hline Cs & 1 & -45.6 & 0.8 & & -44.2 & 1.1 & 2.0 & -28.4 & 1.0 & 2.5 & -33.4 & 1 & 17.9 & -37.2 \\
\hline $\mathbf{R b}$ & 23.0 & -4.0 & 22.7 & 5.9 & -5.3 & 31.8 & 2.3 & 32.7 & 32 & 10.6 & 32.5 & 21.9 & 4.0 & -8.7 \\
\hline $\mathrm{Ba}$ & 390 & 13.6 & 389.0 & 3.0 & 13.2 & 568.7 & 2.4 & 65.4 & 581.2 & 3.1 & 69.1 & 377.3 & 2.1 & 9.8 \\
\hline Th & 2 & -20.0 & 2 & 14.1 & -8.5 & 2.9 & 8.6 & 33.3 & 3.2 & 9.8 & 46.4 & 1.8 & 0.3 & -16.1 \\
\hline $\mathbf{U}$ & 9.0 & -7.5 & 8.7 & 1.3 & -10.7 & 12.3 & 3.2 & 26.8 & 12.9 & 2.8 & 33.1 & 7.7 & 2.0 & -20.3 \\
\hline $\mathrm{Nb}$ & 6 & -13.7 & 5.7 & 5.0 & -18.3 & 11 & 28.5 & 62.8 & 9.8 & 9.1 & 40.1 & 4 & 13.8 & -41.3 \\
\hline $\mathrm{Ta}$ & 0.3 & -13.2 & 0.3 & 32.4 & -13.9 & 1 & 23.9 & 121.0 & 1 & 40.0 & 84.2 & 0.2 & 18.0 & -29.2 \\
\hline La & 13 & -18.7 & 13.3 & 7.5 & -16.8 & 20.5 & 6.6 & 27.9 & 21.7 & 9.0 & 35.3 & 13.3 & 1.8 & -16.7 \\
\hline $\mathrm{Ce}$ & 24.4 & -9.7 & 24.5 & 6.7 & -9.1 & 38.2 & 5.6 & 41.4 & 40.6 & 8.2 & 50.3 & 24.7 & 1.4 & -8.5 \\
\hline $\mathrm{Pb}$ & 59 & -28.8 & 31.8 & & -61.6 & 14.5 & 0.3 & -82.5 & & & -100.0 & 69.0 & 8.7 & -16.6 \\
\hline $\mathrm{Pr}$ & 3.7 & & 3.7 & 5.4 & & 5.8 & 2.6 & & 5.8 & 6.0 & & 3.8 & 3.8 & \\
\hline $\mathrm{Sr}$ & 267 & 31.7 & 269.5 & 3.7 & 32.7 & 378.7 & 3.2 & 86.6 & 380.5 & 6.9 & 87.4 & 259.2 & 2.5 & 27.7 \\
\hline Nd & 15.6 & -2.5 & 15.7 & 4.1 & -1.8 & 24.2 & 1.6 & 51.0 & 25 & 11.2 & 59.0 & 15.8 & 3.3 & -1.0 \\
\hline $\mathrm{Zr}$ & 75 & -44.3 & 151.4 & 0.7 & 13.0 & 161 & 30.7 & 20.2 & 169 & 23.6 & 26.5 & 125.5 & 4.3 & -6.3 \\
\hline Hf & 2 & -43.6 & 3.6 & 2.6 & 0.3 & 4 & 30.4 & 13.3 & 4 & 24.9 & 13.1 & 2.8 & 6.5 & -23.0 \\
\hline Sm & 3.6 & -10.3 & 3.6 & 3.8 & -9.6 & 5.5 & 0.5 & 36.4 & 5.6 & 2.5 & 39.2 & 3.6 & 1.6 & -10.7 \\
\hline Eu & 0.9 & -2.0 & 0.9 & 1.6 & -1.9 & 1.3 & 2.1 & 45.9 & 1.4 & 1.5 & 55.5 & 0.9 & 4.6 & -0.1 \\
\hline Gd & 3.6 & 0.6 & 3.6 & 2.4 & 1.3 & 5.7 & 2.8 & 57.8 & 5.8 & 3.6 & 60.6 & 3.4 & 7.6 & -5.4 \\
\hline Tb & 0.6 & -8.2 & 0.6 & 1.4 & -7.0 & 0.8 & 3.0 & 41.0 & 0.9 & 5.6 & 50.9 & 0.5 & 1.0 & -10.3 \\
\hline Dy & 3.2 & -6.2 & 3.2 & 0.7 & -4.6 & 4.9 & 4.6 & 43.9 & 5.0 & 5.2 & 46.0 & 3.3 & 1.6 & -4.1 \\
\hline$Y$ & 20.3 & 6.6 & 21.2 & 3.4 & 11.7 & 31.3 & 4.3 & 64.9 & 32.1 & 2.5 & 68.7 & 21.5 & 4.7 & 13.4 \\
\hline Ho & 1 & -33.1 & 0.7 & 1.3 & -31.8 & 1.0 & 4.8 & 2.1 & 1.1 & 3.2 & 8.8 & 0.7 & 2.6 & -31.5 \\
\hline $\mathrm{Er}$ & 2.0 & & 2.0 & 1.4 & & 3.0 & 3.9 & & 3.3 & 6.9 & & 2.0 & 1.2 & \\
\hline $\mathrm{Yb}$ & 1.9 & -6.1 & 1.9 & 0.5 & -2.6 & 2.8 & 4.5 & 42.0 & 3.0 & 4.6 & 51.8 & 1.9 & 2.9 & -7.3 \\
\hline Lu & 0.3 & -32.4 & 0.3 & 1.3 & -29.4 & 0.4 & 3.0 & 2.7 & 0.5 & 6.9 & 15.5 & 0.3 & 5.1 & -31.2 \\
\hline Sc & 8 & -11.8 & 7.9 & 5.1 & -11.9 & 11.5 & 3.7 & 28.0 & 12.1 & 6.2 & 34.0 & 8.0 & 1.7 & -10.9 \\
\hline $\mathrm{Ti}$ & & & & & & 1 & 18.9 & & 0.8 & 4.1 & & 0.5 & 5.8 & \\
\hline $\mathbf{V}$ & 51 & 26.1 & 50.6 & 3.7 & 24.1 & 81 & 15.7 & 99.8 & 80.6 & 2.5 & 97.6 & 46.9 & 0.5 & 15.0 \\
\hline $\mathrm{Cr}$ & 16 & -31.1 & 20 & 28.3 & -12.3 & 25 & 58.8 & 9.3 & 35.8 & 5.0 & 54.1 & 5.8 & 4.1 & -74.9 \\
\hline Mn & & & & & & 980.4 & 2.9 & & 1016.9 & 5.1 & & 663.0 & 1.4 & \\
\hline Co & 9.1 & -6.9 & 10 & 10.5 & 2.1 & 15.4 & 3.2 & 57.0 & 16.3 & 2.4 & 66.7 & 10.5 & 0.0 & 7.0 \\
\hline $\mathrm{Ni}$ & 9 & -35.6 & 9.0 & & -35.4 & 21.9 & 9.0 & 56.2 & 24.8 & 6.2 & 76.9 & 15.8 & 3.4 & 13.0 \\
\hline $\mathrm{Cu}$ & 39.3 & -9.9 & 43 & 10.7 & -0.9 & 70.4 & 4.0 & 61.5 & 70.5 & 6.1 & 61.6 & 42 & 10.6 & -3.2 \\
\hline $\mathbf{G a}$ & 9.1 & -8.6 & 9.0 & 6.4 & -10.2 & 12.7 & 3.6 & 26.8 & 13.0 & 6.2 & 30.3 & 8.8 & 3.4 & -11.7 \\
\hline $\mathrm{Zn}$ & 479 & 45.3 & 385 & 16.8 & 17.0 & 460.1 & 9.9 & 39.7 & 533.9 & 4.6 & 62.1 & 303 & 16.1 & -8.1 \\
\hline
\end{tabular}

Table 1 continued 


\begin{tabular}{|c|c|c|c|c|}
\hline \multicolumn{3}{|c|}{ Method D, 400mg } & \multicolumn{2}{|c|}{ Published } \\
\hline$M V(n=2)$ & $\%$ RDS & $\Delta(\%)$ & $M V(n=2)$ & $\%$ RDS \\
\hline 1 & 22.6 & -50.2 & 1.5 & \\
\hline 17.6 & 1.7 & -26.9 & 24.0 & \\
\hline 301.4 & 2.5 & -12.3 & 343.8 & 50.2 \\
\hline 1.6 & 0.3 & -29.0 & 2.2 & \\
\hline 6.0 & 0.6 & -37.7 & 9.7 & \\
\hline 2.7 & 13.7 & -61.0 & 7.0 & \\
\hline 0.1 & 32.2 & -56.5 & 0.3 & \\
\hline 10.9 & 2.3 & -31.7 & 16.0 & \\
\hline 20.6 & 3.4 & -23.8 & 27.0 & \\
\hline 55.8 & 7.9 & -32.7 & 82.8 & 1.3 \\
\hline 3.1 & 5.1 & & & \\
\hline 205.1 & 2.9 & 1.0 & 203 & 46.3 \\
\hline 12.9 & 3.0 & -19.2 & 16.0 & \\
\hline 82.2 & 6.0 & -38.7 & 134.0 & \\
\hline 1.9 & 6.4 & -46.4 & 3.6 & \\
\hline 2.9 & 3.2 & -28.0 & 4.0 & \\
\hline 0.7 & 5.0 & -21.1 & 0.9 & \\
\hline 3 & 11.0 & -22.9 & 3.6 & \\
\hline 0.4 & 2.3 & -28.0 & 0.6 & \\
\hline 2.6 & 3.8 & -22.5 & 3.4 & \\
\hline 17.8 & 5.6 & -6.3 & 19.0 & \\
\hline 0.6 & 5.0 & -44.9 & 1.0 & \\
\hline 1.6 & 4.1 & & & \\
\hline 1.5 & 3.3 & -25.8 & 2.0 & \\
\hline 0.2 & 5.7 & -44.4 & 0.4 & \\
\hline 6.7 & 2.0 & -25.9 & 9.0 & \\
\hline 0.3 & 6.6 & & & \\
\hline 39.5 & 1.7 & -3.3 & 40.8 & 30.9 \\
\hline 6.1 & 4.4 & -73.6 & 23.2 & 46.1 \\
\hline 535.2 & 0.1 & & & \\
\hline 8.4 & 0.3 & -14.7 & 10 & 16.8 \\
\hline 13.0 & 2.9 & -7.3 & 14 & 19.6 \\
\hline 32.6 & 9.1 & -25.2 & 43.6 & 2.1 \\
\hline 7.1 & 0.9 & -29.3 & 10 & \\
\hline 235 & 15.8 & -28.7 & 329.4 & 3.3 \\
\hline
\end{tabular}

